\title{
Autoridad episcopal y autoridad imperial en el período mesobizantino: el caso de Manuel Comneno (1143-1180)
}

\author{
Episcopal authority and imperial authority in the middle byzantine period: the case of \\ Manuel Comnenus (1143-1180)
}

Victoria Casamiquela Gerhold

IMHICIHU-CONICET, Argentina

Fecha de recepción: agosto de 2018. Fecha de aceptación: octubre de 2018.

\begin{abstract}
Resumen
La reestructuración política del Imperio desarrollada por Alexis I Comneno (10811118) se fundó sobre una alianza estratégica entre el poder imperial -que necesitaba consolidar su autoridad frente a las reivindicaciones de la aristocracia laica y de los obispos del sínodo peramente-y la administración patriarcal -que aspiraba a ganar preeminencia dentro de la estructura de la Iglesia. Las consecuencias de la esa alianza fueron fructíferas en diversos sentidos y permitieron la consolidación de la dinastía Comneno en un contexto de gran instabilidad política. A lo largo del siglo XII, sin embargo, los herederos de Alexis I -Juan II (1118-1143) y Manuel I (1143-1180)comenzaron a experimentar crecientes dificultades en su relación con los representantes de la administración patriarcal. A lo largo de este trabajo nos detendremos a analizar el período de reinado de Manuel I con el objetivo de establecer cuál era la situación interna de la Iglesia y de qué manera su relación con el poder imperial influyó en la crisis política propia de fines del siglo XII.
\end{abstract}

\footnotetext{
Abstract

Alexis I Comnenus' (1081-1118) political reorganization of the Empire was based on a strategic alliance between the emperor-who needed to consolidate his authority in the face of the growing power of the lay aristocracy and the bishops of the synod-and the patriarchal administration - which hoped to consolidate its preeminence within the structure of the Church. This fruitful alliance led to the consolidation of the Comnenian dynasty in a context of great political instability. During the $12^{\text {th }}$ century, however, Alexis I's heirs-John II (1118-1143) and Manuel I (1143-1180)-begun to face serious challenges from the members of the patriarchal administration. Throughout this article we will focus on the reign of Manuel I with the aim of reaching a better understanding of the internal situation of the church and of the way in which its relationship with the imperial power influenced the political crisis of the late $12^{\text {th }}$ century.
}

\section{Palabras clave}

Manuel Comneno Iglesia mesobizantina Administración patriarcal Sínodo permanente Obispos provinciales

\section{Keywords}

Manuel Comnenus Middle Byzantine Church Patriarchal Administration Synod Provincial Bishops 
1. Para las circunstancias políticas del reinado de Alexis Comneno y su relación con la iglesia, nos remitimos en términos generales a Frankopan (2007: 1-34), Mullett y Smythe (1996), Angold (1995).

2. Tal como se hará evidente a lo largo del trabajo, la mayor parte de la evidencia conservada proviene del reinado de Manuel I. En casos excepciones, se hará alusión también a circunstancias propias del reinado de Juan II.

3. Para el contexto político general del reinado de Manuel Comneno, nos remitimos a Magdalino (2002).
La configuración político-territorial del Imperio Bizantino a lo largo del siglo XII -especialmente, durante los reinados de Juan II (1118-1143) y Manuel I (1143-1180)fue resultado, en gran medida, de las estrategias implementadas por Alexis I (10811118). Una de las medidas más significativas tomadas por Alexis I fue, sin duda, su alianza con la administración patriarcal, gracias a la cual pretendía lograr no sólo una consolidación de la autoridad imperial frente a las reivindicaciones de autonomía eclesiástica provenientes del sínodo permanente, sino también una rearticulación del territorio imperial a través de la estructura de la Iglesia provincial (i.e. arzobispos, metropolitanos y obispos). ${ }^{1}$ La migración generalizada de las aristocracias laicas provinciales a Constantinopla durante el siglo XI -la llamada "constantinopolitización de la aristocracia"- había causado, en efecto, una ruptura de las dinámicas de organización territorial propias del temprano período mesobizantino, y había expuesto en consecuencia la necesidad de reformular los vínculos políticos y simbólicos que otorgaban cohesión al territorio provincial y unían a las provincias con la capital del Imperio. A partir del reinado de Alexis I, la estrategia imperial de nombrar a los oficiales de la administración patriarcal a la cabeza de las sedes provinciales y de constituir a los nuevos obispos en representantes del poder imperial en provincia había sentado las bases para una reorganización político-territorial fundada sobre una aristocracia eclesiástica leal a los intereses de la dinastía Comneno.

Al momento de la muerte de Alexis I en 1118, sin embargo, la implementación de esta estrategia no había alcanzado aún un desarrollo significativo, y su continuidad bajo los reinados de sus sucesores no resulta del todo clara. ¿En qué medida, en efecto, es posible afirmar que la Iglesia resultó funcional al modelo político -y, específicamente, al modelo de configuración territorial- de los emperadores Comneno durante el siglo XII? La evidencia existente sugiere que la alianza entre el poder imperial y la administración patriarcal no estuvo en el largo plazo a la altura de las expectativas de Alexis I. Por una parte, las fuentes del siglo XII ${ }^{2}$ ilustran que las rivalidades surgidas en administración patriarcal se propagaban fácilmente entre los miembros de la jerarquía episcopal, lo cual traía aparejado que el sínodo se constituyese a menudo en terreno propicio para dirimir querellas privadas. Por otra parte, el hecho de que numerosos arzobispos, metropolitanos y obispos proviniesen de la administración patriarcal no implicaba que no existiesen otros grupos representados dentro del rango episcopal -grupos cuyos intereses eran frecuentemente opuestos a los de la Gran Iglesia- ni que prevaleciese la armonía entre las sedes provinciales y el sínodo permanente. A lo largo de las páginas siguientes nos detendremos, por ende, a analizar la situación interna de la Iglesia durante el reinado de Manuel I -época en la cual es posible observar el punto cúlmine de las estrategias implementadas por Alexis I-y a evaluar sus consecuencias en la política de organización político-territorial promovida por la dinastía Comneno. ${ }^{3}$

\section{La tensión entre los metropolitanos y la administración patriarcal}

A fin de analizar el funcionamiento de la Iglesia bajo el Imperio de los Comneno es necesario abordar en primer lugar la dinámica que orientaba la selección del episcopado provincial. Si bien un número significativo de metropolitanos y obispos procedía de la administración patriarcal, éste no era el caso en todas las sedes provinciales. Los arcontes patriarcales, en efecto, no eran suficientemente numerosos como para cubrir todas las sedes vacantes del Imperio, y, además de esto, muchos de ellos eran reacios a abandonar Constantinopla para ocupar puestos en provincia. Este último punto se encuentra bien ilustrado por las colecciones epistolares. En una carta de c. 1154 dirigida por Jorge Tornikes, entonces hypomnematographos en 
la administración patriarcal, a su amigo Jorge Bourtzes, metropolitano de Atenas, el primero relataba que se había contado entre los tres arcontes patriarcales seleccionados para ocupar la sede metropolitana de Corinto: el refendario Esteban era el primer candidato, el propio Tornikes era el segundo, y el prôtekdikos (cuyo nombre ignoramos) era el tercero. Tornikes, según su propio testimonio, había rechazado la oferta siguiendo el consejo de su amigo Teodoro Pantechnes, y los dos otros candidatos habían hecho lo mismo (Darrouzès, 1970a: epístola $n^{\circ}$ 9, 123-6). Las razones del rechazo se encuentran indirectamente indicadas en epístolas posteriores del mismo Tornikes. En una carta de 1155 al doux de Thrakesion, enviada cuando ya había aceptado hacerse cargo de la metrópolis de Éfeso, Tornikes afirmaba que varios candidatos habían rechazado esa misma sede antes de que él hubiese aceptado hacerse cargo de ella (Darrouzès, 1970a: epístola $\mathrm{n}^{\circ} 20,150-1$ ), y, más tarde, conmovido por las deplorables condiciones de la diócesis, escribía a su amigo Juan Pantechnes para aconsejarle vivamente que permaneciese en Constantinopla y desoyese las promesas que eventualmente pudiesen hacerle en relación con las sedes provinciales.

Debo esta exhortación a tu santidad a causa de la larga amistad que tenemos: incluso si escuchas hablar de un pozo sin fondo del que manan riquezas fuera de Constantinopla, o de una lluvia de oro que cae del cielo, o de los jardines de Alcinoos, o del esplendor que inventa la poesía de los feacios, o de la tierra prometida a Israel, donde fluyen la leche y la miel, no te dejes engañar, cierra tus oídos con cera, no te dejes seducir por estas canciones encantadas. Que el hogar paterno sea para ti el río de oro Paktôlos y los campos elíseos (Darrouzès, 1970a: epístola n² 26, 169-71).

Es evidente que los arcontes patriarcales tenían en cuenta las condiciones materiales, la seguridad militar y el prestigio de la sede al momento de considerar una investidura episcopal. No es sorprendente, en ese sentido, que la mayoría de los obispos formados en la Gran Iglesia que nos son conocidos hayan ocupado sedes en occidente -el arzobispado autocéfalo de Bulgaria, las metrópolis de Heraclea, Tesalónica, Atenas, Patras, Adrianópolis, Neopatras, Philippoupolis, a veces incluso un obispado sufragáneo como Methone-, o en el extremo oeste de Asia Menor, que se encontraba aún bajo control del Imperio -Éfeso, Esmira, Side, Myra. ${ }^{4}$ Las sedes de jerarquía inferior, como así también las que se encontraban seriamente amenazadas u ocupadas por los turcos, eran probablemente cubiertas con individuos externos a la Gran Iglesia -clero de otras iglesias, monjes y laicos quizás-, cuyas pretensiones eran sin duda más modestas. La información sobre las ciudades de Asia Menor es demasiado fragmentaria como para formular conclusiones precisas, pero es significativo que al menos tres metrópolis de frontera -Tyana, Chones, Herakles- y los poco numerosos obispados cuyos titulares nos son conocidos -Sasimes, Balbisa, Pyrgos- hayan sido cubiertos por monjes. El hecho de que el metropolitano de Tyana haya debido consagrar a sus sufragáneos sin la participación de un concelebrante por no haber sido capaz de encontrar uno en la región es ilustrativo en sí mismo de la crítica situación de la Iglesia en oriente. ${ }^{5}$

La vinculación existente entre la administración patriarcal y las sedes provinciales no carecía de consecuencias. Es lógico suponer que los metropolitanos orientales, cuyas sedes estaban ocupadas o amenazadas por los turcos, residían de forma regular en Constantinopla, mientras que los metropolitanos occidentales, así como los del oeste de Asia Menor y los de las islas, permanecían, en virtud de su acuerdo tácito con el poder imperial, regularmente en provincia. Esta distribución geográfica se torna evidente en la composición del sínodo permanente. Si observamos, en efecto, las listas de presencia de las sesiones sinodales del siglo XII, no es difícil percibir que la participación sinodal de los metropolitanos occidentales era casi siempre inferior a la de los metropolitanos orientales.
4. Eustathios de Tesalónica, de hecho, renunció en su sede de Myra hacia 1174, sin duda porque las condiciones de la diócesis eran demasiado difíciles. Es significativo que un diácono tan capacitado y, por otra parte, tan cercano al poder imperial, haya sido nombrado para esa sede. ¿Debemos ver allí una política del poder imperial, buscando consolidar quizás la presencia bizantina en esta región? La posibilidad no es inverosímil, porque otros indicios sugieren que había antiguos miembros de la administración patriarcal a la cabeza de las metrópolis de la región. En lo que respecta a la elevación de algunas sedes a rango metropolitano bajo los Comneno $\mathrm{y}$ al orden de presencia en el siglo XII, cf. Darrouzès (1981: 128-35).

5. El caso de Miguel, metropolitano de Ankara en 1173, es ilustrativo de la situación de las sedes orientales. Éste buscó la autorización del sínodo para abandonar su sede de Ankara, cuya situación se había tornado muy precaria, y para ocupar en su lugar la sede de Kerasounta, cuya situación era aparentemente mejor. V. Grumel ofrece una apropiada síntesis la cuestión: "Pourquoi Michel voulait-il quitter Ancyre, l'une des métropoles les plus élevées du patriarcat byzantin, pour un siège de beaucoup inférieur ? Comme il le déclare lui-même, c'est la pauvreté qui l'y contraignait. Ancyre, depuis longtemps au pouvoir des Turcs, et à peu près vide de chrétiens, ne pouvait suffire à l'entretien de son pasteur. Aussi la détresse de Michel était telle qu'il était sur le point d'abdiquer, quand, une occasion s'offrant, il se souvint de la bonté de l'empereur et lui adressa une requête pour échanger Ancyre contre Kérasonte. L'empereur ordonna au synode d'examiner s'il y avait des empêchements canoniques à ce transfert. On n'en trouva point, car Michel n'avait point été commémoré dans les offices. Le vœu de Michel fut exaucé; il abandonna complètement le siège et le titre d'Ancyre, et devint véritable évêque de Kérasonte, avec tous les droits des évêques ordinaires dans leur église " (Grumel, 1970: 57-96, aquí 169). No sabemos, lamentablemente, cuál había sido la condición de Miguel antes de ser nombrado en el episcopado. Para una descripción detallada de la situación de la Iglesia en las provincias orientales durante los siglos XI y XII, cf. Vroynis (1971: 194-216). 
6. En 1143, Basilio, el metropolitano de Tyana, presentó ante el sínodo acusaciones de bogomilismo contra dos de sus sufragáneos (Leoncio de Balbissa y Clemente de Sasimes). El sínodo, presidido por el patriarca Miguel Kourkouas, examinó las acusaciones durante tres sesiones y concluyó que los acusados eran culpables de numerosos crímenes: herejía de bogomilismo y de iconoclasmo, ordenación anticanónica (habían sido ordenados por Basilio de

Tyana sin la participación de un concelebrante), e infracciones canónicas en las ordenaciones que ellos mismos habían realizado (uno de ellos había ordenado diaconesas). Cf. Gouillard (1978: 5-81, aquí 39-43, 69-81).

7. Empleamos aquí el término "obispo" de forma genérica para hacer alusión a los miembros de la jerarquía episcopal que tomaban parte de las sesiones sinodales; la distinción entre metropolitanos, arzobispos y obispos propiamente dichos no es significativa en este contexto.

Para un análisis de las listas de presencia de las sesiones sinodales y sesiones de firma, cf. Darrouzès (1970b: 57-96, aquí 58-76).

8. El arzobispo de Bulgaria, Juan (Adrián) Comneno, se encontraba presente también, pero el hecho de que su nombre se haya colocado entre los representantes imperiales indica que no asistía a las sesiones (sólo) en su calidad eclesiástica (era el hijo del sebastocrator Isaac, es decir un sobrino de Alexis I), cf. Stieronon (1963: 179-198, aquí 179-92). Cf. Gouillard (1978: 68).

9. Mismo caso respecto al arzobispo de Bulgaria. Cf. Gouillard (1978: 72).

10. Mismo caso para el arzobispo de Bulgaria. Cf. Gouillard (1978: 78).

11. Hay de hecho trece obispos, pero el de Cyzico está nombrado dos veces.

12. Sinaiticus 1117 , estudiada (con las demás) por Darrouzès (197ob: 58-76 y cuadros en 77-9). Las cifras, aquí y en los casos siguientes, casi siempre son aproximadas, porque

los manuscritos no conservan listas de asistencia idénticas.
En 1143, tres reuniones sinodales trataron de manera sucesiva las acusaciones de herejía que el metropolitano de Tyana realizó contra dos de sus sufragáneos. ${ }^{6}$ La primera reunión tuvo una participación total de 13 obispos, ${ }^{7}$ de los cuales dos procedían de occidente y otro procedía de la región norte del Ponto; los diez obispos restantes eran orientales, de los cuales seis representaban sin duda sedes ocupadas por los turcos. ${ }^{8}$ La segunda reunión tuvo una participación total de 12 obispos, tres de los cuales procedían de occidente y uno de los cuales procedía de la región norte del Ponto; los ocho obispos restantes eran orientales, de los cuales seis representaban sin duda sedes ocupadas por los turcos. ${ }^{9}$ La tercera reunión tuvo una participación total de 9 obispos, de los cuales uno procedía de occidente y otro procedía de las islas del Egeo; los siete obispos restantes eran orientales, de los cuales cinco representaban sedes ocupadas por los turcos. ${ }^{10}$

Los sínodos reunidos en 1143-1144 para juzgar la acusación formulada contra el monje Niphon muestran cifras similares. En 1143, sobre un total de 12 obispos, dos procedían de occidente y otro provenía de la región del norte del Ponto; los nueve obispos restantes eran orientales, y seis de ellos representaban sin duda sedes ocupadas por los turcos (Ralles y Potles, 1966: 88). ${ }^{11}$ En 1144, sobre un total de 11 obispos, cuatro procedían de occidente y otro era insular; los seis obispos restantes eran orientales, de los cuales cinco representaban sin duda sedes ocupadas por los turcos (Syntagma V: 90). La misma tendencia es evidente en el sínodo reunido en 1147 para juzgar la acusación formulada contra el patriarca Cosmas Atticos. Sobre un total de 32 obispos, nueve procedían de occidente, tres eran insulares, uno procedía de Italia y otro venía de la región del Ponto; los dieciocho obispos restantes eran orientales, de los cuales nueve representaban probablemente sedes ocupadas por los turcos (Syntagma V: 309-11). El sínodo reunido en 1156 para juzgar los errores de Basilakes, Miguel y Panteugenos revela una tendencia similar. Sobre un total de 23 obispos, seis provenían de occidente, tres eran insulares y uno venía de la región norte del Ponto; los doce obispos restantes eran orientales, de los cuales ocho representaban sin duda sedes ocupadas por los turcos; el metropolitano de Rusia se encontraba presente también (Choniates, Tesoro de la Ortodoxia [= Choniates, Tesoro]: $P G$ 140, col. 148d-149a).

El inicio de las controversias cristológica introdujo sin embargo modificaciones en esta tendencia. Las dos sesiones que trataron las acusaciones contra Soterichos Panteugenos en 1157 muestran un aumento significativo de la participación de obispos occidentales: en la del mes de mayo, sobre un total de 39 obispos, diecisiete procedían de occidente, cinco eran insulares, uno procedía de la región del norte del Ponto y dieciséis eran orientales, de los cuales siete representaban sin duda sedes ocupadas por los turcos (Choniates, Tesoro, col. 18ob-c; Sakkelion, 1880: 317); ${ }^{12}$ en la sesión de firma del verano-otoño de ese mismo año, sobre un total de 34 obispos, once procedían de occidente, cinco eran insulares y dieciocho eran orientales, de los cuales nueve representaban sin duda sedes ocupadas por los turcos (Choniates, Tesoro, col. 197c-391a; Sakkelion, 1880: 327-8; Darrouzès, 1970b: 58-61).

El hecho de que las dos reuniones de 1157 hayan tenido una participación excepcionalmente elevada de obispos occidentales no es sorprendente si se toma en cuenta que la acusación contra Soterichos Panteugenos interesaba especialmente a los miembros (o antiguos miembros) de la administración patriarcal. Sabemos que algunos metropolitanos de la época, como Jorge Tornikes de Éfeso y Jorge Bourtzes de Atenas, eran antiguos oficiales de la Gran Iglesia que habían pertenecido a una facción opuesta a la de Panteugenos; su participación en las sesiones sinodales de 1157, motivada por el deseo de lograr la condena de un antiguo rival, demuestra que las reuniones celebradas ese año estaban destinadas a resolver un conflicto interno de la Gran Iglesia. Las razones de Tornikes y Bourtzes para formar parte 
de esas sesiones sinodales -razones compartidas sin duda por otros metropolitanos procedentes de la administración patriarcal-ilustran en este sentido la existencia de una relación estrecha entre la Gran Iglesia y las sedes occidentales.

El número de metropolitanos occidentales fue también elevado durante la Segunda Controversia Cristológica, lo cual no es sorprendente en vista del papel que la Gran Iglesia desempeñó en el proceso. La primera lista de presencia de 1166 indica una participación total de 39 obispos, de los cuales diecisiete procedían de occidente, seis eran insulares y dos procedían de la región del Ponto; los orientales no fueron esta vez más que catorce en total, de los cuales nueve representaban sin duda sedes ocupadas por los turcos (Choniates, Tesoro, col. 237a-b, para la lista de presencia; col. 237c-248, para las gnômai expresadas en esta sesión). ${ }^{13} \mathrm{La}$ segunda lista de presencia de 1166 indica una participación total de 35 obispos, de los cuales catorce procedían de occidente, seis eran insulares y uno procedía de la región del Ponto; había entre ellos catorce orientales, de los cuales nueve representaban sin duda sedes ocupadas por los turcos (Choniales, Tesoro, col. 256a-b; Darrouzès, 1970b: 63-6). La tercera lista de presencia de 1166 indica una participación total de 50 obispos, de los cuales veinte procedían de occidente, siete eran insulares y uno procedía de la región del Ponto; había además veintidós orientales, de los cuales trece representaban sin duda sedes ocupadas por los turcos (Choniales, Tesoro, col. 257b-261b; Darrouzès, 1970b: 63-6). La cuarta lista de presencia indica una participación total de 19 obispos, seis de los cuales eran occidentales, tres insulares y uno procedente de la región del Ponto; había además nueve orientales, de los cuales cinco representaban sin duda sedes ocupadas por los turcos (Choniales, Tesoro, col. 268c-d; Darrouzès, 1970b: 66-7). La quinta lista de presencia indica una participación total de 29 obispos, de los cuales diez procedían de occidente y tres eran insulares; los orientales eran dieciséis esta vez, de los cuales ocho representaban sin duda sedes ocupadas por los turcos (Choniales, Tesoro, col. 273a; Darrouzès, 1970b: 66-7) ${ }^{14}$ La sexta lista de presencia indica un total de 25 obispos, de los cuales ocho procedían de occidente, tres eran insulares y uno procedía de la región del Ponto; los orientales eran trece en este caso, de los cuales siete representaban sin duda sedes ocupadas por los turcos (Choniales, Tesoro, col. 269b-c; Darrouzès, 1970b: 66-7). La séptima y última lista de presencia de 1166 indica una participación total de 24 obispos, de los cuales doce procedían de occidente y tres eran insulares; los orientales no eran más que nueve esta vez, de los cuales seis representaban sin duda sedes ocupadas por los turcos (Choniales, Tesoro, col. 276c-d; Darrouzès, 197ob: 66-7). ${ }^{15}$

Las listas de presencia de las sesiones sinodales del año 1170, dedicadas a examinar la posición teológica de Constantino de Corfú y del monje Juan Eirenikos, reflejan aproximadamente la misma tendencia general. La sesión del 30 de enero de 1170 no es demasiado representativa: ${ }^{16}$ sobre una participación total de 41 obispos, diez procedían de occidente, seis eran insulares y dos procedían de la región del Ponto; los orientales eran veintitrés, de los cuales catorce representaban sin duda sedes ocupadas por los turcos (cf. Petit, 1904: 479-80). La sesión del 18 de febrero tuvo una participación total de 9 metropolitanos, de los cuales cuatro procedían de occidente y uno era insular; los orientales eran cuatro, de los cuales dos representaban sin duda sedes ocupadas por los turcos (Petit, 1904: 491). La sesión del 20 de febrero tuvo una participación plena de 32 metropolitanos, de los cuales diez procedían de occidente y cinco eran insulares; los orientales eran diecisiete esta vez, de los cuales once representaban sin duda sedes ocupadas por los turcos (Petit, 1904: 489). La sesión del 21 de febrero tuvo una participación total de 51 metropolitanos, de los cuales dieciséis procedían de occidente, ocho eran insulares, uno provenía de Italia y otro de la región del Ponto; los orientales eran veinticinco esta vez, de los cuales catorce representaban sin duda sedes ocupadas por los turcos (Petit, 1904: 488-9).
13. Las dos listas no siempre coinciden, lo cual fue analizado en Darrouzès (1970b: 63-6).

14. Dicha lista y la siguiente se presentan en orden inverso en el Tesoro, pero Petit (1904: 465-493, aquí 71) señaló hace tiempo que hay una transposición de fechas.

15. La lista de firmas final de la Ekthesis, compuesta en varias etapas, no es muy representativa para los aspectos que nos conciernen aquí. Cf., no obstante, Darrouzès (1970b: 67-73).

16. La ausencia de algunos obispos (occidentales, en su mayoría) en esta sesión de deliberación parece explicarse por razones políticas. 
7. Como Grumel lo ha señalado, los nuevos nombres no son simplemente añadidos a los demás (lo que haría pensar en un suplemento de firmas), sino que se consigan en el orden de presencia, lo cual indica su participación de la sesión de firma (Grumel, 1989: nº 1112).

18. Darrouzès, habiendo observado esta ausencia difícil de explicar, consideró ya estas posibilidades (cf. Darrouzès, 1970b: 75-6).
El elevado número de obispos occidentales no es difícil de explicar, puesto que el proceso de 1170, continuación del de 1166, había sido iniciado por el metropolitano de Corfú, un antiguo disdaskalos de la Gran Iglesia. Debe señalarse, en todo caso, que las listas de presencia del año 1170 plantean algunos problemas al momento de evaluar la participación sinodal. Se observa, en efecto, que algunos obispos que no habían participado de la deliberación del 30 de enero ni de la condena del 20 de febrero firmaron sin embargo el acta del 21 de febrero. ${ }^{17}$ Si estos obispos se encontraban en Constantinopla el 21 de febrero para la firma del acta, ¿por qué no participaron de las dos reuniones anteriores? El hecho de que algunos de estos obispos, entre los cuales se cuentan Euthymios de Neopatras, Nicetas de Maroneia y Juan de Tebas, hayan sido opositores al poder imperial durante la controversia de 1166 sugiere que su ausencia de las sesiones del 30 de enero y el 20 de febrero habría tenido una connotación política: ¿debemos pensar que evitaban participar de las sesiones sinodales, pero que fueron forzados a asistir a la sesión de firma para certificar su apoyo a la condena de Constantino de Corfú? ¿O deberíamos pensar que no fueron convocados a las primeras sesiones, o, más bien, que no les fue permitido participar, quizás para no tuviesen la oportunidad de manifestarse en contra del emperador, pero que fueron convocados finalmente para firmar la condena? ${ }^{18}$ En un caso u otro, estos detalles sugieren que los datos facilitados por las listas de presencia ocultan aspectos difíciles de dilucidar. La prudencia se impone, pero, al menos de un modo general, las cifras de la participación sinodal en los juicios de herejía revelan una tendencia general: los obispos orientales -aquellos que hemos identificados como mayoritariamente externos a la administración patriarcal- participaban más frecuentemente de las reuniones del sínodo que los obispos occidentales, excepto cuando el sínodo trataba específicamente cuestiones relativas a la Gran Iglesia. Esta tendencia nos da, por su parte, un primer indicio sobre la articulación entre Constantinopla y las sedes provinciales: los metropolitanos orientales, cuya participación asidua en el sínodo sugiere una presencia regular en Constantinopla, tenían considerable influencia en las decisiones que se tomaban en la capital, mientras que los metropolitanos occidentales, cuya menor participación en el sínodo sugiere menor presencia en la capital, se constituían en los representantes del Estado en el territorio provincial.

El análisis requiere tener en cuenta, sin embargo, que la participación sinodal en los juicios de herejía no es necesariamente representativa de la participación sinodal general durante el siglo XII, ya que asuntos controversiales -como es el caso justamente de la herejía, con todas las connotaciones teológico-políticas que le son propias- atraían sin duda mayor participación sinodal que asuntos de carácter simplemente administrativo, canónico o disciplinario. En ese sentido, las cifras de participación sinodal mencionadas más arriba (todas pertenecientes a procesos de herejía) deben ser comparadas con las cifras de participación de las sesiones sinodales ordinarias a fin de evaluar si la tendencia que hemos observado -mayor participación de orientales en el sínodo (al menos, en las reuniones que no estaban específicamente vinculadas con asuntos relativos a la Gran Iglesia)- tiene un fundamento sólido.

Debe tenerse en cuenta, en todo caso, que el resultado de esta comparación es solamente relativo. El hecho de que la mayoría de las actas de las sesiones ordinarias -es decir, sesiones no relacionadas con los juicios de herejía- pertenezca a la década de 1160 torna difícil hacer una evaluación precisa de la participación sinodal durante el reinado de Manuel Comneno, porque la efervescencia teológica del decenio de 1160 llevaba a Constantinopla obispos que no se habrían encontrado allí en otras circunstancias. En 1166, en efecto, tuvieron lugar las sesiones sinodales pertenecientes a la Segunda Controversia Cristológica, cuyos inicios se remontan a años anteriores; en 1168 tuvo lugar la condena del diácono Basilio 
Hagiopaulites, acusado de haber escrito en contra del dogma oficial aprobado en 1166; entre 1170 y 1171 tuvieron lugar, por último, las condenas de Constantino de Corfú y de Juan Eirenikos, también justificadas por su resistencia al dogma oficial. Es así que el decenio de 1160, marcado por las sucesivas etapas de la Segunda Controversia Cristológica, vio una afluencia excepcional de obispos provinciales hacia la capital, una afluencia que se vio reflejada en las reuniones ordinarias del sínodo: numerosos obispos que se dirigían a Constantinopla en razón de la Controversia Cristológica aprovechaban sin duda su presencia en la capital para participar también de otras reuniones del sínodo en las que se discutían asuntos canónicos o disciplinarios.

Este último factor podría explicar por qué observamos una diferencia tan pequeña entre el número de obispos orientales y de obispos occidentales en las sesiones sinodales ordinarias desarrolladas entre 1164 y 1169. En la mayor parte de las sesiones, por cierto, los orientales fueron más numerosos que los occidentales y los insulares, pero, de un modo general, las tres grandes regiones del Imperio se vieron representadas casi en términos de igualdad. ${ }^{19} \mathrm{Si}$ observamos, sin embargo, las listas de presencia de otros decenios del reinado de Manuel Comneno, encontramos que las diferencias son significativas. Antes de la década de 1160 no tenemos más que una lista de presencia -la de noviembre de 1145-, la cual, a pesar de las cifras muy modestas de participación, se vio claramente dominada por los orientales. ${ }^{20}$ La ausencia de otras listas de presencia no permite sacar conclusiones definitivas, pero es posible señalar en todo caso que las cifras de esta sesión ordinaria reafirman la tendencia sugerida por las listas de presencia de los juicios de herejía del mismo decenio de 1140 (contra los obispos de Capadocia, contra Niphon y contra Atticos): los orientales lograron casi siempre duplicar (y a veces triplicar o cuadruplicar) el número de occidentales y de insulares.

Hacia finales del decenio de 1160, por otra parte, el número de obispos occidentales en las reuniones ordinarias del sínodo comenzó a descender lentamente. En la sesión de noviembre de 1169 el número de obispos orientales cuadruplicó el número de occidentales, ${ }^{21}$ y en la siguiente sesión de noviembre de 1170 el número de orientales duplicó el de los occidentales. ${ }^{22}$ Esta tendencia se vio interrumpida por una sesión de enero de 1171 en la que el número de occidentales sobrepasó el de los orientales, sin que sea posible explicar este cambio repentino, ${ }^{23}$ pero la tendencia reaparece nuevamente en la sesión de mayo de 1172, en la cual el número de orientales cuadruplicó el de los occidentales, ${ }^{24}$ y se ve reafirmada por las tres sesiones siguientes: la de julio de 1173 , en la que el número de orientales casi triplicó el de los occidentales; ${ }^{25}$ la de enero de 1177 (sesión de firma en la carta sinodal al católicos de Armenia), en la que el número de orientales casi triplicó el de los occidentales; ${ }^{26} \mathrm{y}$, por último, la de septiembre de 1177, en la que no hubo más que un solo occidental frente a nueve orientales. ${ }^{27}$ Es posible concluir, por lo tanto, que tras la década de 1160 la participación sinodal retornó hacia la tendencia que había prevalecido durante el decenio de 1140: los orientales eran, casi sin excepción, mucho más numerosos que los occidentales (y los insulares) en las sesiones del sínodo permanente.

Estas cifras, naturalmente, no dan cuenta de todas las variables existentes. Sabemos que algunos obispos orientales que participaban regularmente del sínodo -los de Cyzico, Nicomedia, Abydos, Mileto y Parion- no procedían de sedes ocupadas o seriamente amenazadas por los turcos, ${ }^{28}$ mientras que los obispos de las regiones amenazadas -los de Tyana o Chones- optaban por permanecer en provincia. ${ }^{29}$ Sabemos también que algunos metropolitanos occidentales e insulares -los de Heraclea, Philippes, Selymbria, Arcadiopolis, Creta y Methymnos- eran miembros activos del sínodo permanente. ${ }^{30}$ Sabemos, por último, que ciertos metropolitanos provinciales residían en Constantinopla pero no asistían a las sesiones sinodales,
19. Para las listas de presencia de este decenio, Cf. Grumel (1989: $n^{\circ}$ 1055); Papadopoulos-Kerameus [= AIS] (1891-1898, IV: 106-7, sesión de febrero de 1164);

(continúa en página 119)

20. Sobre un total de 6 obispos, cuatro eran orientales, uno era occidental y el otro era insular. Cf. Grumel (1989: $n^{\circ}$ 1019).

21. Sobre un total de 17 obispos, doce eran orientales, tres eran occidentales y dos eran insulares. Grumel (1989: $\mathrm{n}^{\circ}$ 1086); PapadopoulosKerameus (AIS, IV: 107-8),

22. Sobre un total de 15 obispos, nueve eran orientales, cuatro eran occidentales y dos eran insulares (Grumel, 1989: $n^{\circ}$ 1118; Syntagma III: 440-4).

23. Sobre un total de 21 obispos, nueve eran orientales, diez eran occidentales y dos eran insulares. (continúa en página 120)

24. Sobre un total de 18 obispos, doce eran orientales, tres eran occidentales y tres eran insulares. Cf. Grumel (1989: $n^{\circ} 1125$ ).

25. Sobre un total de 26 obispos, dieciséis eran orientales, seis (o siete) eran occidentales, dos (o tres) eran insulares, y uno procedía de la región del Ponto. La procedencia de uno de los obispos sigue siendo dudosa y hace difícil especificar el número de los occidentales y de los isleños. Cf. Grumel (1989: $\left.n^{\circ} 1126\right)$.

26. Sobre un total de 16 obispos, once habrían sido orientales, cuatro habrían sido occidentales, y uno habría sido insular. La lectura de algunos nombres presenta problemas. Juan "de Herakles" es nombrado como Juan "de Arakliaj" (continúa en página 120)

27. Sobre un total de 11 obispos, nueve eran orientales, uno era occidental y otro era insular. Cf. Grumel (1989: $n^{\circ} 1134$ ).

28. Es preciso suponer que residían en Constantinopla, puesto que incluso si sus sedes no se encontraban demasiado lejos de la capital, es difícil creer que hayan viajado para las sesiones sinodales y regresado a sus ciudades luego de cada una de las reuniones.

29. Como podemos deducir del conflicto de Basilio de Tyana con sus sufragáneos (que seguían estando también instalados en sus sedes) y del testimonio de Choniates sobre Nicetas de Chones (Van Dieten, 1975 219) [= Choniates, Historia].

30. Es posible que algunos de éstos (especialmente los que procedían de la región de Tracia) no hayan residido de manera permanente en la capital. La proximidad entre las sedes de Tracia y Constantinopla les habría permitido sin duda viajar de manera regular. 
31. Según Darrouzès, el metropolitano Clemente de Rusia, nombrado en 1147 , se encontró fuera de su sede hasta el momento de su dimisión, en 1155 (Darrouzès, 1970a: 215, n. 22); hacia 1154 se habría encontrado en Constantinopla (ibíd); sin embargo, el hecho de que haya ordenado y establecido sufragáneos sugiere que se habría dirigido incidentalmente a su sede (Grumel, 1989: $n^{\circ}$ 1040). Si es cierto que residía en Constantinopla, al menos por períodos prolongados de tiempo, este obispo no participaba del sínodo permanente, dado que las listas de presencia que se han conservado para el período de su episcopado no lo mencionan.

32. Especialmente en los primeros juicios del siglo, que no parecen haber interesado mucho a los miembros de la administración patriarcal. En estos casos, el número de obispos orientales duplicaba, triplicaba y cuadruplicaba el número de obispos occidentales, y los orientales procedían en su mayor parte de sedes que debían estar ocupadas o muy amenazadas por los turcos.

33. Pese al aumento del número de occidentales, los orientales eran casi siempre más numerosos; el número de orientales y occidentales fue el mismo en una de las sesiones, y los occidentales fueron más numerosos en dos sesiones. como es el caso de Clemente de Rusia. ${ }^{31}$ Sin embargo, las estadísticas son los suficientemente elocuentes como para permitirnos ratificar la tendencia general antes observada, que ahora podemos definir con mayor precisión en función de tres puntos principales: 1) La mitad de las sesiones sinodales (ordinarias o extraordinarias) desarrolladas bajo el reinado de Manuel Comneno tuvo una participación mucho más significativa de obispos orientales que de obispos occidentales; ${ }^{32}$ 3) En las sesiones restantes, no hubo una gran diferencia entre el número de obispos orientales y occidentales: los orientales prevalecieron casi siempre, pero los occidentales los sobrepasaron algunas veces; ${ }^{33}$ 3) El aumento del número de obispos occidentales en las sesiones sinodales coincide con los decenios de 1150 y 1160, cuando el sínodo se ocupó de controversias que interesaban especialmente a los miembros (o antiguos miembros) de la administración patriarcal.

Estos datos parecen ratificar así una disociación geográfica entre aquellos metropolitanos orientales que residían en Constantinopla y asistían regularmente al sínodo permanente y aquellos metropolitanos occidentales que se dirigían rara vez a Constantinopla y cuya participación de las sesiones sinodales respondía a intereses específicos. El hecho de que la alta participación de los obispos occidentales se encuentre vinculada a asuntos relativos a la administración patriarcal sugiere, por su parte, que los metropolitanos occidentales eran, al menos en su mayoría, antiguos oficiales de la Gran Iglesia, lo cual se ve confirmado de hecho en todos los casos de metropolitanos occidentales que nos son conocidos. Este último grupo -occidental (o insular) y vinculado a la administración patriarcal- queda así relativamente bien identificado; pero ¿qué es lo que podemos decir sobre el otro grupo de obispos -orientales su mayoría y no vinculados en generalmente a la administración patriarcal-que es tan significativo durante las sesiones sinodales del siglo XII?

Es difícil establecer si existía una cooperación, o al menos cohesión interna, dentro de este último grupo. La característica que parece haberles sido común -el hecho de no provenir, en su mayor parte, de la administración patriarcal- no es suficiente para definirlos como un conjunto coherente, pero es muy posible que esa característica común haya jugado un rol en el desarrollo de una identidad compartida. El rol privilegiado que los miembros de la administración patriarcal detentaban dentro del Imperio de los Comneno, en efecto, despertaba sin duda la animadversión de aquellos que no gozaban de los mismos privilegios, y no es inverosímil que esa misma animadversión haya promovido la emergencia de un vínculo entre estos metropolitanos de orígenes diversos que compartían el hecho de encontrarse excluidos de la alianza imperial.

La identificación de estos metropolitanos como un grupo coherente y bien definido permitiría, de hecho, explicar algunos acontecimientos que resultan difíciles de comprender de otra manera. En una carta que Juan Tzetzes dirigió a Manuel Comneno para defender al patriarca Atticos de sus enemigos políticos, éste señalaba que "ciertos individuos" se quejaban de que el chartophylax ocupase un lugar junto a ellos, dado que su presencia "se había convertido en una mala influencia, y en un

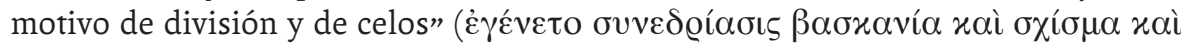

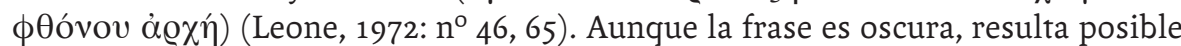
advertir que su autor alude a la animosidad de ciertos obispos respecto a las prerrogativas del clero patriarcal (representado en este caso por el chartophylax). Esa alusión, sin embargo, es difícil de interpretar: ¿cómo debe entenderse, en efecto, el conflicto existente entre los obispos y la administración patriarcal en época de Manuel Comneno? Bajo Alexis I, como es bien sabido, los metropolitanos (recelosos de la eclesiología imperial y leales a las ambiciones del patriarca Cerulario) habían sido renuentes a aceptar el ascendiente ganado por los oficiales de la Gran Iglesia, y la preeminencia adquirida por el chartophylax en las ceremonias eclesiásticas se había constituido en un motivo tradicional de conflicto entre los dos grupos. Al 
comienzo del reinado de Manuel Comneno, sin embargo, esa confrontación ya había sido superada: los antiguos miembros de la administración patriarcal, convertidos en metropolitanos, habían substituido en gran medida a la vieja guardia de metropolitanos rebeldes dentro del sínodo. Pero, si este era el caso, si los nuevos metropolitanos del sínodo procedían efectivamente de la Gran Iglesia, ¿cómo se explica que Tzetzes haya hecho alusión a la "celos" de los obispos hacia las prerrogativas del clero patriarcal, como si los obispos y el clero patriarcal constituyesen todavía grupos opuestos?

Otros datos reafirman, sin embargo, el testimonio de Tzetzes. Es posible observar que los miembros de la administración patriarcal respondían de forma agresiva cuando el sínodo se inmiscuía en sus disputas internas, como lo ilustra el caso de "Hierotheos" -el adversario de Nicéforo Basilakes- quien definió al sínodo como "la taberna de

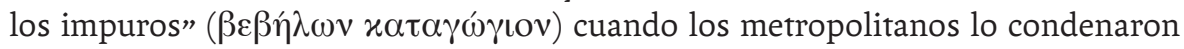
por difamar al patriarca (Garzya, 1984: 92). De la misma manera, es probable que las intervenciones más radicales del sínodo en el patriarcado constantinopolitaino -las que causaron la deposición de Cosmas Atticos y de Nicolás Mouzalon- deban ser entendidas en términos de una rivalidad entre el sínodo y la Gran Iglesia. Pero, una vez más, ¿cómo se explica esta rivalidad? ¿Es posible pensar que el grupo de metropolitanos que no procedía de la administración patriarcal se servía eventualmente de su ascendiente sobre el sínodo para confrontar al clero de la Gran Iglesia (y al propio patriarca de Constantinopla)?

El juicio contra el patriarca Atticos, mejor conocido que el juicio contra Mouzalon, nos permite examinar esta última posibilidad. Es evidente, en primer lugar, que la acusación contra Atticos fue iniciada por los metropolitanos: el semeioma de 1147 hace explícito que la denuncia provino de "algunos de los muy sagrados obispos" ( $\tau \hat{\omega} v$

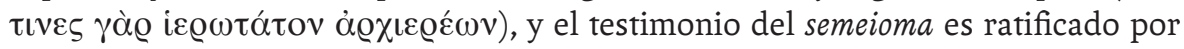
otras fuentes (Syntagma V: 308). Nicetas Choniates identifica una "facción de obispos" contemporáneos a Atticos que eran "adversarios de la virtud y enemigo del campeón de la virtud" (es decir, de Atticos) (Choniates, Historia: 90), y Cinnamos señala que el emperador había recibido personalmente a "los obispos" para conocer su opinión sobre el caso (Meineke, 1836: 65 [= Cinnamos]). Aunque la identidad de estos obispos no nos es conocida, es claro al menos que formaban parte del sínodo permanente, ya que no existe otra forma de explicar la condena pronunciada rápidamente por

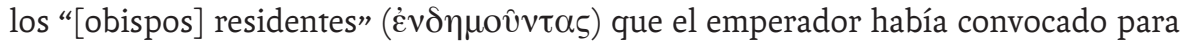
juzgar el caso, ni el hecho de que Atticos haya excomulgado hacia el final del juicio "al sínodo que se había reunido para deponerlo, afirmando que [estos obispos] eran aduladores del emperador" (Choniates, Historia: 81).

A falta de datos más concretos sobre la identidad de los acusadores de Atticos, es interesante tener en cuenta las sedes que se encontraban representadas durante el proceso. El semeioma de 1147 nos indica la participación de nueve obispos occidentales -los de Larisa, Dristra, Cristopolis, Bizye, Karabizye, Heraclea, Nicopolis, Traianoupolis y Arcadiopolis-, de tres obispos insulares -los de Rodas, Methimnos y Kios- de un obispo italiano -el de Mesina-, de un obispo de la región del Ponto -el de Cherson-, y de dieciocho obispos orientales -los de Cesárea de Capadocia, Éfeso, Cyzico, Sardis, Nicomedia, Nicea, Calcedonia, Claudiopolis, Laodicea, Myra, Kerasounta, Tyanes, Neocesárea, Antioquía de Psidia, Parion, Amastris, Apamea y Gothia-, de las cuales once representaban sin duda sedes ocupadas por los turcos (Syntagma V: 309-11).

A primera vista, la lista de presencia no nos permite sacar conclusiones demasiado precisas sobre estos obispos. No sabemos, en primer lugar, cuál fue la posición de cada uno de ellos en la controversia, y, aún si supiéramos que todos apoyaron la 
condena, seguiría siendo difícil establecer quiénes fueron los promotores de la acusación contra el patriarca. Es probable, en efecto, que la adhesión del emperador a los detractores de Atticos haya influenciado la toma de posición de obispos que no habían integrado originalmente la facción de los adversarios del patriarca, y, a causa de ello, la identidad de los acusadores queda oculta en el conjunto indistinto de signatarios. Es preciso tener en cuenta, en todo caso, que el juicio contra el patriarca no puede ser en modo alguno desvinculado del juicio contra el monje Niphon, y, por ende, la revisión de este último puede aportar algunas precisiones sobre la identidad de los enemigos de Atticos.

El semeioma de 1147 hace explícita la relación entre los dos juicios al expresar que los obispos, "no poco escandalizados de ver [al patriarca Atticos] en relación con un hombre [Niphon] condenado con anterioridad en un sínodo por hereje y transmisor de doctrinas extrañas a la Iglesia" (Syntagma V: 308), se habían apresurado a denunciar la amistad entre Atticos y Niphon. El testimonio de Cinnamos ratifica esa conexión. Este autor señala que Manuel Comneno, habiendo escuchado las denuncias sobre la asociación entre Atticos y Niphon, recibió a "los obispos de manera individual" a fin de consultar "a cada uno de ellos cuál era su opinión sobre la piedad de Niphon" (Cinnamos: 65). El interrogatorio individual habría estado destinado quizás a evitar que la facción de adversarios de Atticos -esa facción mencionada por Choniates e insinuada también por el semeioma de 1147-influyese sobre la opinión del sínodo. Cinnamos insiste aún más sobre el caso de Niphon. Una vez que la acusación contra Atticos fue llevada ante la justicia, el emperador preguntó a los obispos - "no individualmente esta vez, sino a todos juntos"- cuál era su opinión sobre este monje (Cinnamos: 65-6). La respuesta da cuenta de un consenso generalizado: "[los obispos] acusaron al hombre categóricamente de ser un hereje" (Cinnamos: 66).

Es evidente que la condena de Niphon constituyó el punto de partida del juicio contra el patriarca Atticos. El sínodo habría tomado a mal sin duda la indiferencia del patriarca respecto a la muy dura condena sinodal contra Niphon, según la cual le estaba prohibido "socializar con otros, al punto de que ni siquiera la palaba o el saludo le pueden ser dirigidos, por no mencionar las reuniones o las oraciones, o cualquier otra actividad que tenemos la costumbre de realizar en compañía de otros" (Syntagma V: 308). La intervención del sínodo en 1147, necesaria para castigar la desobediencia del patriarca tanto como para ratificar la culpabilidad de Niphon, sugiere en ese sentido que los obispos que se interesaban por la condena de Atticos eran, al menos en parte, los mismos que se habían interesado anteriormente por la condena de Niphon. La identidad de estos obispos no nos es conocida, pero sabemos al menos que formaban una facción relativamente fuerte en una época en que el sínodo se encontraba dominado por los representantes de las sedes orientales.

La relación entre el juicio contra Niphon y el juicio contra Atticos provee un primer indicio significativo, pero es necesario considerar además que la figura de Niphon no puede ser desvinculada a su vez del antiguo juicios contra los obispos sufragáneos del metropolitano de Tyana. Al fin y al cabo, Niphon había sido acusado de bogomilismo y condenado a reclusión en el monasterio de Peribleptos por haber intentado defender a los sufragáneos de Tyana-quienes, por su parte, habían sido previamente acusados de la misma herejía. Una vez más, por consiguiente, es razonable pensar que los metropolitanos interesados en las condenas de Niphon y Atticos eran, al menos en parte, los mismos que anteriormente se habían interesados por la condena de los sufragáneas de Tyana. Esta hipótesis puede verificarse a partir de un análisis comparativo de los signatarios de los sucesivos sínodos. 


\begin{tabular}{|c|c|c|}
\hline Sínodo de 1143 & Sínodo de 1143-4 & Sínodo de 1147 \\
\hline Gothia $1 / 2 / 3$ & Gothia $1 / 2$ & Gothia \\
\hline Tyana 2 & Tyanes $1 / 2$ & Tyana \\
\hline Antioquía de Psidia 1/2/3 & Antioquía de Psidia 1 & Antioquía de Psidia \\
\hline Cyzico $1 / 2 / 3$ & Cyzico 1 & Cyzico \\
\hline Nicomedia $1 / 2$ & Nicomedia 1 & Nicomedia \\
\hline Nicea 1 & Nicea 1 & Nicea \\
\hline- & Laodicea 2 & Laodicea \\
\hline- & Amastris 2 & Amastris \\
\hline- & Parion 2 & Parion \\
\hline Heraclea 1 & - & Heraclea \\
\hline Bizye 2 & - & Bizye \\
\hline Methymnos 3 & - & Methymnos \\
\hline Karabizye 3 & - & Karabizye \\
\hline Éfeso $1 / 3$ & - & Éfeso \\
\hline Ankara $1 / 2 / 3$ & Ankara 1 & - \\
\hline Garella $1 / 2 / 3$ & Garella 1 & - \\
\hline Dyrrachion 2 & Dyrrachion $1 / 2$ & - \\
\hline Alaneia 2/3 & Alaneia 1 & - \\
\hline Madyta 2 & Madytos $1 / 2$ & - \\
\hline Mesembria $1 / 2$ & Mesembria 1 & - \\
\hline
\end{tabular}

Tal como lo ilustran las listas sinodales, varios de los metropolitanos que participaron de la deposición del patriarca Atticos en 1147 habían participado anteriormente ya sea de los sínodos que condenaron Niphon -como es el caso de los de Gothia, Tyana, Laodicea, Amastris, Parion, Antioquía de Psidia, Cyzico, Nicomedia, Nicea-, o de los sínodos que condenaron a los sufragáneos de Tyana -como es el caso de los de Gothia, Tyana, Antioquía de Psidia, Éfeso, Cyzico, Nicomedia, Nicea, Heraclea, Bizye, Karabizye y Methymnos-, o bien de los dos sínodos anteriores -como es el caso de los de Gothia, Tyana, Antioquía de Psidia, Cyzico, Nicomedia y Nicea. Es posible que, en algunos casos, esta repetición de sedes sea solo una coincidencia, pero al menos sabemos que la presencia del metropolitano de Tyana en tres de los juicios no fue azarosa: el primero de los tres juicios fue iniciado por él, y es muy probable que él mismo haya desempeñado también un papel significativo en los juicios contra Niphon y Atticos. Es preciso señalar además que, aunque la geografía de su sede sugiere que el metropolitano de Tyana vivía como refugiado en Constantinopla, su nombre no figura en otras listas sinodales del siglo XII. Esta participación selectiva refuerza la impresión de un interés particular por los juicios de Niphon y Atticos -un interés que no resulta sorprendente, ya que nadie podía estar más interesado en la condena de los defensores o potenciales defensores de los sufragáneos depuestos que el metropolitano responsable de su deposición.

El caso de otros metropolitanos es igualmente sugestivo. Es posible observar, por ejemplo, que la sede de Gothia está representada en los tres juicios y en todas las sesiones de cada juicio -es decir, en las tres sesiones contra los sufragáneos de Tyana, en las dos sesiones contra Niphon y en la sesión contra Atticos. La sede de Antioquía de Psidia, por su parte, está representada también en los tres juicios y en casi todas las sesiones de cada juicio - en las tres sesiones contra los sufragáneos de Tyana, en una de las sesiones contra Niphon y en la sesión contra Atticos. El 
34. Si tal fuera el caso, es posible que hayan visto la intervención de Atticos en favor de Niphon como una interferencia del patriarcado en contra de sus intereses. El patriarca, sin embargo, no debe ser necesariamente identificado con la administración patriarcal. Atticos había sido diácono (sin duda en la Gran Iglesia) antes de ser patriarca, lo que podría identificarlo de manera relativamente segura con los intereses de la administración patriarcal, pero hay que tener en cuenta en todo caso que Atticos tenía igualmente opositores dentro de la Gran Iglesia. Los

detalles del caso son, en cualquier caso, demasiado oscuros para que se puedan extraer de ellos conclusiones más precisas. detalle no sugiere, a primera vista, nada en particular, porque otras sedes-Cyzico, Nicomedia, Nicea- también están representadas en todos los juicios. Sin embargo, existe entre estos dos casos una diferencia fundamental: Cyzico, Nicomedia y Nicea son sedes que vemos representadas frecuentemente durante el siglo XII, sin duda porque sus metropolitanos residían o permanecían durante largos períodos en la capital. Gothia y Antioquía de Psidia, sin embargo, son sedes que, como Tyana, se encuentran casi exclusivamente relacionadas con los juicios que estamos tratando, ya que no son nombradas más que en raras ocasiones en otros procesos del mismo siglo. Un vínculo tan estrecho entre estas sedes y los procesos contra los sufragáneos de Tyana, Niphon y Atticos sugiere que sus metropolitanos se contaban entre los que apoyaban las acusaciones de Basilio de Tyana y entre los que confrontaron, finalmente, al patriarca Atticos.

Por más que la identidad de los obispos no puede ser definida con precisión, resulta evidente al menos que nos encontramos frente a una preponderancia de obispos orientales. Más allá de un metropolitano insular y de otro procedente de la región del Ponto, contamos trece metropolitanos orientales -de los cuales ocho representaban sin duda sedes ocupadas por los turcos- que participaron de más de uno de los tres procesos, mientras que sólo cinco metropolitanos occidentales asistieron a más de un proceso. Los tres metropolitanos que más relacionados parecen estar al proceso -los de Tyana, Gothia y Antioquía de Psidia- eran también orientales, lo que no es sorprendente si se toma en cuenta que la controversia había tenido sus inicios en la diócesis oriental de Tyana.

Existe aún otro detalle. Tyana, Antioquía de Psidia y Gothia se encontraban, en razón de su posición geográfica, entre las sedes menos atractivas de la época. Es difícil creer que los arcontes patriarcales, que eran reacios a aceptar sedes como Corinto o Éfeso, hayan aceptado ocupar sedes perdidas a manos de los turcos o ubicadas en la línea de frontera. Aunque no es posible afirmarlo con certeza, es probable que los acusadores del patriarca Atticos hayan sido metropolitanos orientales que no procedían de la administración patriarcal, quizás esos mismos metropolitanos "celosos de las prerrogativas del chartophylax" que estaban descontentos con los privilegios de la Gran Iglesia. ${ }^{34}$

La división de los metropolitanos según su procedencia, su formación y su estatus ofrece una perspectiva interesante para abordar la cuestión de las rivalidades dentro de la Iglesia, pero la escasez de información la torna elusiva y difícil de analizar. Es preciso que nos detengamos, por ende, a considerar las sedes ocupadas por los antiguos arcontes de la Gran Iglesia -sedes que nos son generalmente mejor conocidas. En el caso de estos últimos sabemos al menos que los conflictos que las oponían estaban generalmente vinculados a las antiguas rivalidades de sus metropolitanos en el seno de la administración patriarcal. Es, por consiguiente, sobre los complejos asuntos internos de la Gran Iglesia que nos detendremos a continuación.

\section{Las tensiones dentro de la administración patriarcal}

La preeminencia que la Gran Iglesia había adquirido a partir del reinado de Alexis Comneno había profundizado en gran medida los conflictos de poder dentro del clero patriarcal -conflictos cuyas consecuencias se hacían sentir en toda la estructura de la Iglesia. Al menos tres controversias desarrolladas en el siglo XII bajo el reinado de Manuel Comneno ilustran esas divisiones del patriarcado constantinopolitano. 


\section{1/ Cosmas Atticos y el clero de Santa Sofía}

Para empezar, sabemos que el patriarca Atticos tuvo diferencias con el chartophylax de la Gran Iglesia, Juan Pantechnes, a causa de una discusión canónica. En respuesta a una consulta sobre la abstinencia de carne los miércoles y viernes entre Pascua y Pentecostés, Atticos desestimó la opinión emitida previamente por el chartophylax, que había reafirmado la prohibición de carne, y sostuvo la opinión contraria. Según el patriarca, cuya interpretación pretendía seguir la de San Basilio, no debían introducirse distinciones entre los días de la Cincuentena, porque era "como un solo día de fiesta"; la prohibición de carne sólo era una legislación monástica que no tenía por qué aplicarse a los laicos (Papadopoulos-Kerameus, 1909: 273-84; Grumel, 1989: $\mathrm{n}^{\circ}$ 1024; Tiftixoglou, 1969: 25-72, aquí 57-8).

No sabemos cuáles fueron las consecuencias de estas desavenencias con el chartophylax, pero está claro al menos que los problemas de Atticos con los oficiales patriarcales no acabaron allí. En la carta que Juan Tzetzes dirigió a Manuel Comneno para defender la inocencia de Atticos, el primero denunciaba que los arcontes de la Gran Iglesia se contaban entre los enemigos del patriarca (Tzetzes, Epistulae: ${ }^{\circ} 46,65-7$ ), lo cual se ve reafirmado por el testimonio de Nicéforo Basilakes. Este último describía en un escrito titulado Investigación contra Bagoas la forma en que dos oficiales de la Gran Iglesia -a los que identifica con los sobrenombres de "Ierotheos" y "Bagoas"habían conspirado contra Atticos: los oficiales habían vertido miel sobre los santos íconos y acusado al patriarca de haber sido el autor de este sacrilegio (Basilakes, Bagoas: 92). ${ }^{35} \mathrm{La}$ identidad de los enemigos del patriarca, lamentablemente, es desconocida y no es posible determinar si este segundo episodio tuvo relación con el del chartophylax.

Parece evidente, en todo caso, que las disidencias internas de la administración patriarcal no tuvieron relación con la deposición de Atticos. El semeioma del año 1147 y los relatos de Choniates y Cinnamos explicitan, en efecto, que los acusadores del patriarca fueron los obispos del sínodo y no los oficiales de la Gran Iglesia. Podría pensarse, desde ya, en la existencia de una vinculación entre los enemigos del patriarca en la administración patriarcal y los obispos que iniciaron las denuncias -un gran número de obispos, en última instancia, procedía la Gran Iglesia y mantenía relaciones con ésta-, pero el hecho de que el proceso contra Atticos haya estado tan relacionado con el proceso contra el monje Niphon (cf. sección 1) sugiere que el conflicto no tenía sus orígenes en las querellas de la administración patriarcal. En todo caso, los problemas de Atticos con sus oficiales son muy ilustrativos de los conflictos que dividían al clero de la Gran Iglesia. Vemos así, por un lado, a la facción de los enemigos del patriarca, integrada por "Ierotheos" y "Bagoas" y quizás también por Juan Pantechnes, y, por otra parte, a la facción de los defensores del patriarca, cuyo único nombre conocido es el de Basilakes. La lógica de las alianzas y enfrentamientos dentro de la administración patriarcal es poco clara, pero los casos siguientes ilustran que éstos podían ser mucho más complejos de lo que el caso de Atticos nos permite entrever.

\section{2/ Jorge Tornikes y Soterichos Panteugenos}

Hacia 1154, cuando era aún hypomnematographos en la administración patriarcal, Jorge Tornikes escribió a su amigo Jorge Bourtzes de Atenas para ponerlo al corriente de las más recientes controversias del clero patriarcal. El último conflicto se había iniciado después de la muerte del patriarca Teodoto (ocurrida ese mismo año), cuando un oficial patriarcal, Soterichos Panteugenos, y sus partidarios quisieron negar, debido a la falta de dinero, los honores fúnebres a los restos del patriarca (Darrouzès, 1970a: $n^{\circ} 7,208-11$ y n. 7, 208). La razón alegada para ello constituía, según Tornikes, una nueva blasfemia de Panteugenos: habiendo percibido que la mano derecha del patriarca se había ennegrecido durante la enfermedad que había precedido a su
35. La identificación del "Cosmas" nombrado en el texto no es segura, sobre todo en razón del empleo regular de seudónimos en la obra de Basilakes. El editor de texto sugirió que el nombre podría designar al propio Basilakes, pero Angold ha argumentado sin embargo que la descripción que Basilakes hace del personaje refleja más bien a la figura de un patriarca. Para los detalles de la posición de Angold, que seguimos aquí, cf. Angold (1995: 80, n. 38). 
muerte, Panteugenos se había atrevido a afirmar que esa alteración era propia de los bogomilos, como él lo sabía "por haber examinado muchas tumbas de los partidarios de esa herejía y haber encontrado que era así" (Darrouzès, 1970a: $\mathrm{n}^{\circ} 7,210-11$ ).

Tornikes reaccionó de inmediato contra Panteugenos, movido por esta ofensa contra la memoria de Teodoto. Tornikes sabía, por un lado, que la mano ennegrecida del patriarca se explicaba por razones biológicas, y, por otro lado, había oído personalmente al patriarca cuando éste comentaba su mal en público, sin ninguna intención de ocultarlo. Pero lo que molestaba particularmente a Tornikes era la falta de escrúpulos de Panteugenos al momento de perseguir sus intereses políticos - "QQué estupidez, o qué locura, no vacilar siquiera a exponerse en persona al delito de violación de tumbas, únicamente para ensuciar el nombre de otro!" (Darrouzès, 1970a: $\mathrm{n}^{\circ} 7,210-11$ )-, una falta de escrúpulos de la que Tornikes o sus amigos habrían sido probablemente víctimas en el pasado.

Panteugenos se mostró ofendido por la actitud de Tornikes y respondió con un panfleto, una "comedia vergonzosa", en la que injuriaba a sus opositores con el lenguaje "del mercado y de lo vulgar"; poco después, Panteugenos coronó su ofensiva vinculando a sus enemigos a la acusación que ya había lanzado contra el patriarca Teodoto, es decir, acusándolos de bogomilismo. La descripción de Tornikes deja entrever que Panteugenos tenía un buen número de partidarios - "los compañeros de juego de "valeroso"'-, pero su identidad es desconocida en la mayor parte de los casos - al menos en lo que respecta a los miembros de la administración patriarcal. Sabemos, en todo caso, que Panteugenos tuvo el apoyo del metropolitano de Rusia, y, quizás, de los metropolitanos de Side y de Heraclea, que circulaban en esa época en la Gran Iglesia y que fueron más bien favorables a Panteugenos durante la Primera Controversia Cristológica. Los partidarios de Tornikes tampoco son bien conocidos. Éste menciona a un cierto Eustathios, que habría sido, según la identificación probable de Darrouzès, el futuro obispo de Tesalónica (Darrouzès, 1970a: 212, n. 16); sabemos, por otra parte, que Tornikes recurrió durante la Primera Controversia Cristológica a dos antiguos amigos de la administración patriarcal para garantizar la condena a Panteugenos: uno de ellos era Aristenos, gran oikonomo y dikaiodotes; el otro era Boukinator, grammatikos del patriarca y hypomimneskôn. Con toda probabilidad, éstos habrían sido aliados de Tornikes durante la disputa contra Panteugenos que nos ocupa aquí. Fuera de la administración patriarcal, Tornikes tuvo el apoyo de Jorge Bourtzes de Atenas y de sus hermanos, así como de un cierto Cristóforo, que podría haber sido el metropolitano de Mitylene del mismo nombre, tal como lo ha sugerido Darrouzès (Darrouzès, 1970a: 211, n. 13).

\section{3/ Basilio, Miguel y Nicéforo Basilakes}

Juan Cinnamos no deja lugar a dudas sobre el carácter personal de la querella que enfrentó en 1156 al diácono Basilio contra Nicéforo Basilakes y el prôtekdikos Miguel. Según su relato, Basilio "deseaba insultar subrepticiamente en sus sermones a algunos de los que se habían enfrentado con él recientemente" -es decir, Basilakes y Miguely se sirvió de su puesto de didaskalos del Evangelio para lograrlo (Cinnamos: 176). La naturaleza exacta de los ataques que Basilio lanzó contra sus rivales no nos es conocida, pero sabemos al menos que éstos "se encolerizaron a causa del ataque", puesto que "siendo tan cultos sufrían las burlas de un individuo como ese" (Cinnamos: 177). Basilakes y Miguel decidieron responder a la ofensiva de Basilio mediante una acusación de herejía. Según Cinnamos, "cuando Basilio celebraba su liturgia habitual en la iglesia del Apóstol San Juan el Teólogo, fuera de la ciudad, [Basilakes y Miguel] fueron hasta allí para escucharlo con una atención tramposa, llena de malicia", y, en el momento en que Basilio declaró que "el Hijo de Dios y el Espíritu Santo eran uno y el mismo y recibían el sacrificio [de la Eucaristía] con el Padre, tomaron nota de 
la expresión inmediatamente y fueron por todas partes burlándose de él y diciendo que Basilio introducía dos hipóstasis, una que era sacrificada y otra que recibía el sacrificio" (Cinmamos: 176-7). Basilakes y Miguel recibieron el apoyo de Soterichos Panteugenos, quien puso toda su capacidad dialéctica y retórica al servicio de su posición cristológica -la del Padre que recibe, solo, el sacrificio de Cristo.

El sínodo, reunido ese mismo año para tratar la cuestión, dio la razón al diácono Basilio y procuró disuadir a Basilakes, Miguel y Panteugenos de sus errores teológicos; Basilio recuperó su puesto, del que había sido suspendido, y sus adversarios fueron censurados. Pero Panteugenos, que acababa de ser elegido patriarca de Antioquía, no estaba dispuesto a dejar pasar el asunto. Fue así que redactó un panfleto criticando al sínodo y pidió que el emperador interviniese personalmente para resolver el conflicto. Su solicitud fue escuchada, pero el sínodo reunido en 1157 ante Manuel Comneno ratificó, sin embargo, la decisión anterior y condenó a Panteugenos a ser depuesto de su dignidad de patriarca antioqueno (Cinnamos: 177 ). ${ }^{36}$

Como lo hemos señalado ya, los conflictos dentro de la administración patriarcal tenían consecuencias para el conjunto de la jerarquía eclesiástica. Los antiguos arcontes patriarcales convertidos en metropolitanos seguían estando vinculados a menudo con las facciones de la Gran Iglesia y reproducían sus divisiones dentro del sínodo. Algunas de las controversias teológicas del siglo nos permiten entrever la forma en que los conflictos internos del patriarcado constantinopolitaino (como las que acabamos de describir) se convertían en conflictos dentro de rango de los metropolitanos. A lo largo de las páginas siguientes abordaremos dos ejemplos ilustrativos de este proceso: la Primera y Segunda Controversia Cristológica desarrolladas durante el reinado de Manuel Comneno.

\section{Las tensiones entre los metropolitanos}

La Primera Controversia Cristológica, desarrollada a partir del enfrentamiento de Basilio y sus partidarios contra Miguel, Basilakes y Panteugenos a partir de 1156 (ver sección 2), arroja alguna luz sobre las facciones existentes dentro del sínodo. Es evidente que esta controversia, nacida de una rivalidad personal entre colegas de la administración patriarcal, concernía especialmente a los oficiales de la Gran Iglesia, algunos de los cuales se habían convertido en metropolitanos. Ya en el proceso de 1156, que había sido el antecedente al juicio contra Panteugenos de 1157, la presencia de miembros de la administración patriarcal es mencionada por el semeioma con mucho detalle:

Había una venerable multitud de estos arcontes que son amados por Dios, y de la otra jerarquía sagrada estaban los siguientes: el gran archidiácono, el gran oikonomo, el chartophylax, el sakkelarios, el protonotario, el kanstrisios, el referendario, el hypomnimatographos, el primer ostiario, el didaskalos del Evangelio, el hypomimniskôn, el primer arconte de la Iglesia, el epi tôn deeseôn, el segundo ostiario, el segundo arconte de la Iglesia, los muy doctos notarios patriarcales, el segundo de los diáconos y otros (Choniates, Tesoro, col. 152C). ${ }^{37}$

En el concilio de 1157 se examinó en primer lugar a los diáconos, y fue sólo después de que éstos hubieron "expresado con un alma y con una lengua su acuerdo y su conformidad con el tribunas imperial y sagrado en las cuestiones del dogma" que se procedió a examinar a Nicéforo Basilakes y a Panteugenos (Choniates, Tesoro, col. 185 d). Sin embargo, la rivalidad entre los arcontes patriarcales no estaba confinada a los límites de la Gran Iglesia. Los miembros de la administración patriarcal que se habían
36. La declaración de los aliados de Panteugenos, señalada por Choniates, es sin embargo dudosa. Cf. Grumel (1989: n 1039).
37. En la mayoría de las actas, la participación está indicada de forma general, sin el detalle de los asistentes (cf., por ejemplo, Gouillard, 1978: 68, 72 y 78; Syntagma V: 88, 90, 308; Choniates, Tesoro, col. 180c). 
38. La figura de Jorge de Larisa presenta algunos problemas.

En primer lugar, no es siempre mencionado por los manuscritos (el Vatic. 680 no lo nombra en la sesión del 12-13 de mayo de 1157; pero su presencia se indica no obstante en el Pat .336 y en el Sin. 1117). En segundo lugar, la sede de Larisa es mencionada en 1156 , pero no conocemos el nombre del metropolitano. En cualquier caso, dado que sólo hay un año de diferencia entre los dos sínodos, puede suponerse que el metropolitano Jorge que encontramos en 1157 era el mismo que participó en el sínodo del año anterior. Cf. Darrouzès (1970b: 59).

39. La edición de Mai (Choniates, Tesoro, col. 193d) consigna "Cesárea", pero, dado que el metropolitano de Cesárea había sido ya mencionado entre los que condenan al acusado, hay que seguir sin duda la edición de Sakkelion y leer "Neocesárea" (Патльакі̀ Вıß入ıөп́кп, р. 325). convertido en metropolitanos guardaban vínculos con sus antiguos colegas y, por lo tanto, mantenían una cierta lealtad a alguna de las facciones que dividían al clero patriarcal. Las controversias surgidas en la Gran Iglesia devenían, por ende, en controversias ente los metropolitanos -entre aquellos metropolitanos, al menos, que provenían de la administración patriarcal-y causaban a su vez conflictos entre las sedes provinciales.

El ejemplo mejor conocido es el de Nicéforo Basilakes y el prôtekdikos Miguel (véase sección 2), cuya controversia con el diácono Basilio involucró la participación de numerosos obispos procedentes de la administración patriarcal. Uno de estos obispos fue Soterichos Panteugenos, antiguo diácono de la Gran Iglesia convertido en patriarca antioqueno, que se adhirió, en virtud de una alianza cuya esencia se nos escapa, a la causa de Basilakes y Miguel. Eustathios de Dyrrachion, cuya identidad no es bien conocida, se puso también de parte de éstos en la sesión sinodal de 1156, lo cual nos permite pensar que habría sido a su vez un antiguo miembro de la administración patriarcal opuesto al partido de Basilio (Choniates, Historia: 211).

La misma controversia ofrece otros datos sobre las facciones en juego. El papel del metropolitano Constantino de Rusia, quien llevó la cuestión de la supuesta herejía de Basilio ante el sínodo, es lamentablemente poco claro: Constantino expuso durante la sesión sinodal opiniones teológicas opuestas a las de los acusados, pero no es evidente que haya actuado por deseo expreso de defender al didaskalos Basilio o de perjudicar a Miguel, a Basilakes o a Panteugenos. Otras figuras son, en cambio, mejor conocidas. Jorge Tornikes de Éfeso, cuya oposición a Panteugenos se remontaba a la época en la que ambos ocupaban puestos en la administración patriarcal (véase sección 2), expresó con vehemencia su apoyo a las opiniones teológicas del metropolitano de Rusia, y, por lo tanto, su condena a Panteugenos. Según el acta del sínodo, "el muy santo arzobispo de la metrópolis de Éfeso (...), lleno de un celo divino que no alcanzaba a contener, declaró que estaba de acuerdo con el metropolitano de Rusia, y afirmó que persistiría firme en dicha confesión incluso hasta la muerte" (Choniates, Tesoro, col. 152-b). La posición de Jorge Bourztes de Atenas, amigo de Tornikes y antiguo opositor a Pantaugenos dentro de la administración patriarcal, no figura en el acta sinodal, pero no puede dudarse de que éste fue igualmente partidario de los enunciados del metropolitano de Rusia. En estos dos casos, la toma de posición de los metropolitanos no estaba vinculada a las figuras originales del conflicto -Basilio, Miguel y Basilakes-, sino que estaba claramente motivada por la figura de Panteugenos, cuya adhesión a Miguel y a Basilakes había incitado la participación sinodal de otros metropolitanos procedentes de la administración patriarcal.

La cuestión, en efecto, sea torna más clara cuando la controversia se centra en la figura de Panteugenos. En el sínodo de mayo de 1157, dos arzobispos -los de Bulgaria y Chipre-y cinco metropolitanos - los de Cesárea, Corinto, Atenas, Larisa y Adrianópolispidieron la deposición de Panteugenos de su dignidad de patriarca antioqueno. Dos de estos metropolitanos -los de Atenas y Larisa- habían participado del sínodo de 1156: podemos reafirmar así que Jorge Bourtzes de Atenas se contaba aún entre los enemigos de Panteugenos, y que Jorge de Larisa, cuya identidad es desconocida, ${ }^{38}$ era también uno de los rivales del acusado. Los metropolitanos de Cesárea, Corinto y Adrianópolis se sumaron, pese a su ausencia del sínodo de 1156, a la acusación contra Panteugenos, y el de Adrianópolis en particular mostró gran interés por el desarrollo del juicio: tomó parte de la delegación enviada a Panteugenos cuando éste no quería presentarse ante el sínodo, y alentó al parecer la presencia de algunas figuras cercanas a él durante la sesión del 13 de mayo -Jorge, lector en Adrianópolis,

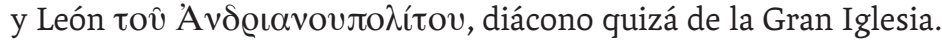

El acta sinodal de 1157 menciona también a siete metropolitanos que pidieron más tiempo para reflexionar antes de expresar su opinión: los de Heraclea, Cyzico, Side, Tesalónica, Neocesárea, ${ }^{39}$ Philippes y Laodicea. ¿Podemos pensar que estos metro- 
politanos eran favorables a Soterichos Panteugenos? El caso del metropolitano de Tesalónica es el más sugestivo. Dado que el prôtekdikos Miguel, cuyas denuncias contra

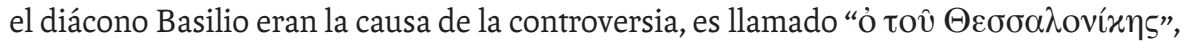
es posible que tuviese vinculación (probablemente familiar) con el arzobispo Basilio de Tesalónica. Es curioso, por cierto, que Basilio no haya participado de la sesión de 1156, donde Miguel fue examinado por el sínodo, y que haya asistido sin embargo a las sesiones de 1157, que estaban centradas en la figura de Panteugenos. Su ausencia en 1156 es difícil de explicar, pero su asistencia al sínodo de 1157 puede haber estado determinada por un interés específico en el resultado de la controversia: si la posición teológica de Panteugenos era reconocida como ortodoxa, Miguel -con quien Basilio aparentemente tenía relación-iba a verse también reivindicado. Podría pensarse, en ese sentido, que Basilio participó del sínodo con el propósito de tomar partido en favor de Panteugenos, y que su actitud dilatoria fue sólo un recurso para permitir a Panteugenos repensar su posición frente a las acusaciones.

El caso del metropolitano de Tesalónica, en todo caso, no es el único en sugerir una inclinación especial de los metropolitanos provinciales a favor de Soterichos Panteugenos. Puede observarse que los metropolitanos de Side y de Attaleia no participaron en el siglo XII más que en los dos sínodos de 1157, relativos al caso de Panteugenos. ¿Debemos pensar que esta participación selectiva es mera coincidencia? Es posible. Pero es posible también que, como en el caso de Basilio de Tesalónica, estos metropolitanos hayan asistido al sínodo con el objetivo explícito de pronunciarse sobre la figura de Panteugenos. Side y Attaleia, de hecho, se encuentran en la región sur de Asia Menor, donde Manuel Comneno habría querido consolidar la presencia bizantina, lo que sugiere al menos su posible procedencia de la administración patriarcal. La posición de Attaleia durante el juicio no nos es conocida, pero el metropolitano de Side se cuenta entre los que se mostraron reticentes a condenar a Panteugenos. La evidencia es demasiado escasa como para sugerir que se trataba de un antiguo miembro de la administración patriarcal sumado a la causa del acusado, pero podemos al menos retener esa posibilidad.

¿Qué puede decirse, por otra parte, con respecto a otros metropolitanos que el semeioma nos muestra como "indecisos" frente a la condena de Panteugenos? Los metropolitanos de Heraclea, Cyzico, Neocesárea, Philippes y Laodicea participaban regularmente de los sínodos, y nada indica que hayan participado de las sesiones de 1157 debido a un interés particular por la figura de Panteugenos. A pesar de todo, no puede descartarse que hayan sido antiguos miembros de la administración patriarcal favorables a la facción del acusado, como lo sugiere al menos su actitud dilatoria. El acta del sínodo de 1157 no consigna, por otra parte, la posición de 15 metropolitanos -Attaleia, Lemnos, Herakles, Nicomedia, Mokessos, Naupactos, Apamea, Corfú, Paronaxia, Mesembrie, Bizye, Arcadiopolis, Parion, Selymbria y Karabizye. Sabemos que el metropolitano de Parion acompañó a los de Corinto y Adrianópolis como delegado sinodal ante Panteugenos, pero no es posible afirmar nada sobre su posición en el conflicto (Choniates, Tesoro, col. 196a-b)..$^{40}$

La lista de signatarios del Tomo en el que se consignó la condena de Panteugnenos, elaborada algún tiempo después de la reunión sinodal, añade algunos datos de interés. Es posible observar que seis de los metropolitanos que habían tomado parte de la sesión del mes de mayo -los de Mesembria, Bizye, Selybria, Karabizye y Derkos- no firmaron el Tomo, mientras que algunos otros que no habían estado presentes en esa sesión -los de Nicea, Calcedonia, Claudiopolis, Amastris, Patras y Methymnos- firmaron sin embargo la condena a Panteugenos. La primera lista no ofrece un interés particular, porque no sabemos cuál había sido la posición de los obispos allí mencionadas durante la discusión sinodal. No hay razones para pensar, por otra parte, que su ausencia de la lista de signatarios tenga un significado particular: es posible que
40. El hecho de que los obispos de Corinto y Adrianópolis hayan sido enemigos de Panteugenos (los dos habían solicitado su deposición) sugiere que el de Parion habría compartido su posición. La delegación, destinada a ejercer presión sobre Panteugenos, parece haber sido bastante hostil a éste. 
41. León de Nicea: “ $\varepsilon i ́$ kaì

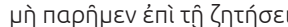

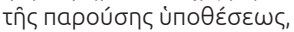

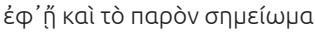

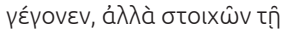

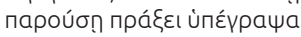
kaì aútó $\varsigma^{\prime \prime} ;$ Constantino de

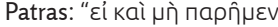

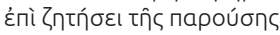

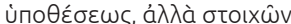

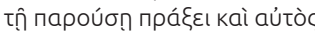
únદ́үрача"; Sakkelion (1880: 327-8); Darrouzès (1970b: 60).

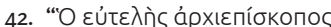

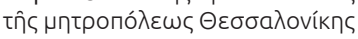

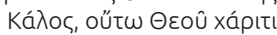

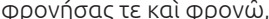

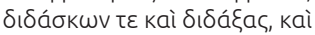

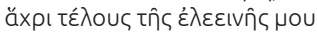

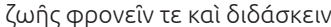

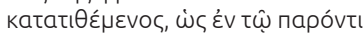

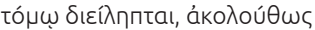

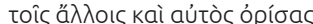
únćүрачa"; Sakkelion (1880: 328). el retraso de la sesión de firma ocasionado por la muerte del patriarca Constantino Chliarenos les haya impedido simplemente permanecer en la capital (Choniates, Tesoro, col. 197c-201a; Sakkelion, 1880: 327-8; Darrouzès, 1970: 59-61).

La segunda lista posee mayor interés. Puede pensarse, en efecto, que la presencia en Constantinopla de los signatarios que no habían tomado parte de la discusión no fue sólo una simple coincidencia: algunos metropolitanos, que no habían llegado a la capital para participar de los debates, habrían logrado sin embargo hacerse presentes en Constantinopla para participar al menos de la firma del Tomo. Si ese fue el caso, debemos asumir por ende que todos estos signatarios tenían un interés particular (y, por ende, una posición tomada) en el proceso. León de Nicea y Constantino de Patras firmaron utilizando la fórmula "aunque no he estado presente durante el debate de la fórmula a partir de la cual el presente semeioma fue elaborado, estoy de acuerdo ( $\sigma \tau \mathrm{\tau} \chi \hat{\omega} v)$ con el dogma y he firmado" mientras que Constantino de Calcedonia y Miguel de Methymnos se limitaron a

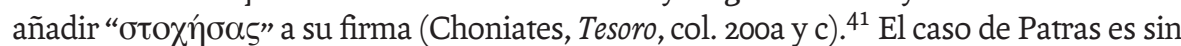
duda el más significativo, porque la sesión de firma del Tomo es la única en la que encontramos el nombre de esta sede durante el siglo XII: es posible pensar así en una conexión entre el metropolitano Constantino y Soterichos Panteugenos.

La lista de firmas ofrece otros datos de interés. León de Adrianópolis, que había tomado parte de los debates sinodales, no logró llegar sin embargo a la sesión de firmas. A causa de ello, firmó más tarde añadiendo una nota:

Aunque no he firmado más arriba, en el rango de la sede que me corresponde, porque estaba ausente de la ciudad en el momento en que mis colegas firmaban, pero dado que mi opinión ha sido consignada anteriormente en el presente Tomo en buena y debida forma, dado que he participado personalmente de los debates con los demás, he considerado que es mi deber confirmar con mi firma el voto que he emitido; no me preocupa el lugar en el que coloco mi firma, ya que esto no involucra ningún perjuicio para la posición jerárquica de mi sede (Darrouzès, 1970b: 6o yn. 7).

La posición del metropolitano de Adrianópolis ya se había hecho evidente durante las sesiones el 12 y 13 de mayo, y las palabras que acompañan su firma vienen a reafirmar hasta qué punto era partidario de la condena de Panteugenos. Quedan escasas duda, en ese sentido, de que León se contaba entre los enemigos más acérrimos del acusado.

Podemos observar, por otra parte, que el metropolitano de Tesalónica fue el único de los signatarios en hacer una profesión explícita de su adhesión al dogma: "el humilde metropolitano de Tesalónica, Kalos, por la gracia de Dios he creído y creo, he enseñado y enseño, y prometo creer y enseñar hasta el final de mi pobre vida lo que está contenido en el presente Tomo; habiendo ratificado, he firmado siguiendo a los otros" (Choniates, Tesoro, col. 200b)..$^{42}$ Esta profesión de fe resulta sorprendente. Por un lado, encontramos un nuevo metropolitano en la sede de Tesalónica -Kalos-, y, por otro lado, observamos que este metropolitano era sospechoso a los ojos del sínodo. Es posible que el cambio del titular en la sede de Tesalónica haya sido consecuencia de la posición (aparentemente) favorable a Panteugenos de la que Basilio había dado pruebas durante la sesión del mes de mayo, pero, si ese fue el caso, no parece que los acusadores hayan logrado poner a esa sede episcopal bajo su control. El hecho de que se haya solicitado al nuevo metropolitano que aclarase su adhesión al Tomo sugiere, en efecto, que éste era sospechoso de pertenecer al mismo grupo de opinión que su predecesor.

A pesar de que los detalles del juicio se nos escapan, el proceso contra Panteugenos ilustra al menos la forma en que las rivalidades nacidas en la administración patriarcal pasaban al nivel de los metropolitanos. Los casos de Basilio de Tesalónica, de Jorge 
Tornikes de Éfeso, de Jorge Bourztes de Atenas y de Soterichos Panteugenos constituyen ejemplos significativos de esta dinamica: una vez integrados a la jerarquía episcopal, los antiguos oficiales patriarcales seguían estando vinculados a las facciones políticas a las que habían pertenecido en la Gran Iglesia y se involucraban a veces en las querellas que se suscitaban alli. ${ }^{43}$ Las consecuencias para las iglesias metropolitanonas no eran menores: algunos metropolitanos era depuestos, como fue al parecer el caso de Eustathios de Dyrrachion en 1156 y de Basilio de Tesalónica en 1157; otros se veían forzados a aceptar una cierta posición teológico-política, como fue el caso de los metropolitanos de Heraclea, Cyzico, Side, Tesalónica, Neocesárea y Laodicea en 1157; otros, por último, quedaba sin duda en malos términos con sus colegas del sínodo permanente y veían su posición política debilitada. La procedencia de la administración patriarcal, que era positiva en razón de la formación y de los contactos con que se dotaba los metropolitanos, podía convertirse así en una fuente importante de dificultades para los eclesiásticos dentro de la estructura de la Iglesia.

La Segunda Controversia Cristológica, iniciada por Manuel Comneno en 1166 en un intento por preservar las relaciones diplomáticas con occidente, ofrece otro ejemplo ilustrativo de la misma situación. El testimonio de Cinnamos y la Ekthesis de 1166 muestran que la definición doctrinal de Manuel I había suscitado profundas divisiones en la administración patriarcal. ${ }^{44} \mathrm{El}$ patriarca Lucas Chrysoberges se había alineado con el emperador, y su ejemplo fue seguido por algunos de sus diáconos -no más de seis en total, según Cinnamos (p. 253). La Ekthesis menciona que el refendario, el hypomnematographos, el hieromnimôn, el epi tôn gonatôn, el hypomimniskon, el primer arconte de la Iglesia y el segundo ostiairio expresaron su acuerdo con "los patriarcas" -es decir, con la posición imperial- cuando fueron interrogados durante la primera sesión sinodal; el chartophylax demostró también, por sus enunciados doctrinales, que se encontraba de parte del emperador, y empleó además explícitamente la fórmula

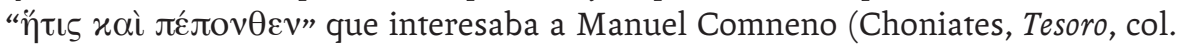
248c-249b; Darrouzès, 1970: 63-6);4 el gran oikonomos no hizo explícita su adhesión al patriarca ni empleó la fórmula de compromiso, pero su profesión debió ser considerada aceptable porque no se volvió sobre ella más tarde. La profesión de fe de otros miembros de la administración patriarcal fue, sin embargo, considerada "oscura"

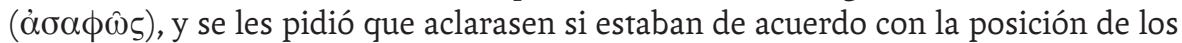
patriarcas: el gran sakkelarios, el kanstrisios, el maestro de retórica y el gran skeuophylax respondieron afirmativamente, y este último adjuntó a su declaración la fórmula de

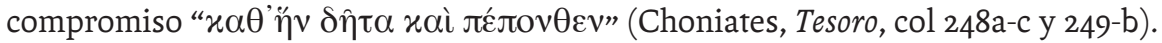

La Ekthesis parece señalar así una división dentro de la administración patriarcal entre aquellos oficiales que eran leales al poder imperial y aquellos que eran (o habían sido) opositores. Esta primera impresión, sin embargo, no se ajusta a la realidad. Es preciso señalar, en efecto, que las autoridades del sínodo no hicieron un examen sistemático de los miembros de la administración patriarcal: el examen comprendió al primer arconte, pero no al segundo arconte; al segundo ostiario, pero no el primer ostiario; al maestro de retórica, pero no a los didaskaloi; y otros oficiales, como el gran archidácono, los notarios, el epi tôn deeseôn, etc., no fueron incluidos en el interrogatorio. ¿Por qué este examen selectivo? La respuesta más probable es que el sínodo examinó sólo a aquellos miembros de la administración patriarcal cuya posición doctrinal era sospechosa de ser contraria a la del poder imperial. Habría que concluir, por ende, que todos los oficiales interrogados durante la primera sesión sinodal eran adversarios del dogma oficial, aunque algunos de ellos hayan estado más comprometidos que otros: el hecho de que se haya aceptado sin mayor insistencia la profesión de fe del oikonomos, del chartophylax y de los ocho oficiales que se adhirieron de inmediato al patriarca sugiere que éstos no estaban seriamente implicados, mientras que la insistencia en la opinión del gran skeuphylax, del gran sakkelarios, del kanstrisios y del maestro de retórica podría sugerir al contrario que éstos eran los instigadores de la oposición.
43. Resulta sorprendente encontrar un cierto número de obispos sufragáneos entre los asistentes a las dos sesiones sinodales que trataron el asunto de Soterichos Panteugenos. Lamentablemente, su identidad no es conocida (con excepción, quizás, de Constantino de Dalisandos), y tampoco la de sus metropolitanos. Sabemos, al menos, que los obispos de Patara, Traecheia, Irkania y Antandros asistieron al sínodo con sus metropolitanos, que habrían compartido sin duda su posición en la controversia. ¿Esto nos permite pensar que procedían también de la Gran Iglesia? Es imposible afirmarlo, pero la posibilidad puede ser tomada en cuenta. Los obispos restantes (los de Dalisandos, Argos, Dimitriadis y Arta) asistieron al sínodo sin sus metropolitanos. ¿Habrían sido enviados a participar de las sesiones por sus metropolitanos, o tenían algún interés personal en el asunto? Una vez más, es imposible afirmarlo con certeza.

44. Como es bien sabido, la Segunda Controversia Cristológica se inició en 1166, cuando el diplomático bizantino Demetrio de Lampe cuestionó la interpretación latina de Juan 14:28 (según la cual el Hijo se declaraba inferior al Padre a causa de su naturaleza humana), y Manuel Comneno reunió a los teólogos de la corte para ratificar la interpretación latina.

45. Para el empleo de la

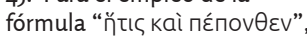
cf. Gouillard (1967: 219-20). 
46. Éstos habrían criticado el decreto imperial y se habrían visto obligados a firmar un formulario de conformidad [para los detalles del caso, cf. Petit (1904: 470); Grumel $\left.\left(1989, n^{\circ} 1063 y^{\circ}{ }^{\circ} 1067\right)\right]$. La fórmula "habiendo alejado de él toda sospecha", que se emplea en ambos casos, reafirma, por otra parte, que su adhesión al poder imperial afirmada en la sesión del 2 de marzo había seguido siendo sospechosa, y que era necesario reafirmarla.

47. El criterio utilizado para delimitar esos grupos puede ser fácilmente puesto en cuestión, porque el hecho de adherir a la opinión de otro obispo no era inhabitual en las sesiones sinodales. (continúa en página 120)
El poder imperial parece haber estado seriamente preocupado por la posición de estos últimos. Es significativo que las autoridades sinodales hayan insistido en la opinión del gran sakkelarios, ya que éste había mencionado en su primera declaración

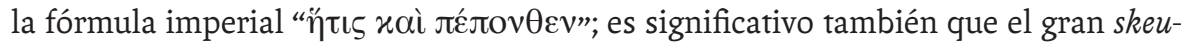
ophylax haya añadido en su segunda declaración la misma fórmula " $\chi \alpha \theta$ ”

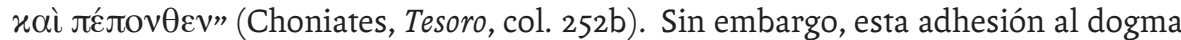
oficial, forzada por la presión del poder imperial, no parece haber sido decisiva. Pese a su aceptación de la fórmula de compromiso, pese a su adhesión explícita a la doctrina "de los patriarcas", las actas posteriores dejan entrever que el gran skeuophylax Juan Pantechnes y el kanstrisios Samuel continuaban siendo sospechosos ante las autoridades sinodales (Choniates, Tesoro, col. $268 \mathrm{~d}$ y $269 \mathrm{~b}-\mathrm{c}$ ). ${ }^{46}$ Esta sospecha sugiere al menos que estos oficiales se mantuvieron discretamente relacionados con la oposición.

Los disidentes que vemos representados en la Ekthesis no eran, en todo caso, la única facción dentro de la administración patriarcal. Otro grupo, menos numeroso sin duda, era leal a los intereses del poder imperial: encontramos allí a los diáconos mencionados por Cinnamos, algunos de los cuales debían coincidir con los oficiales patriarcales que no fueron entrevistados por el sínodo; sus identidades no nos son conocidas, pero este posible que Miguel Ankhialos, el futuro patriarca de Constantinopla, se haya contado entre ellos. Esta división, que evoca la de la Gran Iglesia en tiempos de la Primera Controversia Cristológica, afectaba sin duda la toma de posición de los obispos, en particular de aquellos que procedían de la administración patriarcal.

La profesión de fe realizada por la jerarquía episcopal durante la primera sesión sinodal permite identificar también algunos grupos bastante definidos entre los metropolitanos. Observamos así que los metropolitanos de Cyzico, Creta, Hierapolis, Abydos y Mesembria declararon compartir la opinión del metropolitano de Heraclea; del mismo modo, los metropolitanos de Trebizonda, Hierapolis, Derkos y Ankhialos declararon compartir la opinión del metropolitano de Creta; y, por último, los metropolitanos de Amaseia, Abydos y Mileto declararon compartir la del metropolitano de Nicomedia. He aquí tres pequeños grupos centrados en torno de Heraclea, Creta y Nicomedia respectivamente, cuya estrecha relación es evidente. El metropolitano de Hierapolis declaró, en efecto, estar de acuerdo con el metropolitano de Heraclea y con el de Creta; el metropolitano de Abydos declaró estar de acuerdo con el metropolitano de Heraclea y con el de Nicomedia; el metropolitano de Creta declaró, por último, estar de acuerdo con el de Heraclea, y, por lo tanto, todos los que habían adherido a él-Trebizonda, Derkos y Ankhialos- compartían necesariamente la posición de Heraclea (Choniates, Tesoro, col. 237c-248). ${ }^{47}$ No hay, por ende, más que un solo grupo con tres subdivisiones, cuyos miembros tenían todos una misma posición en la controversia. Esa posición no es difícil de establecer: puede observarse que los

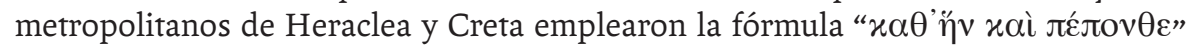
-tácitamente aceptada, por ende, por todos aquellos que se adhirieron a ellos. El metropolitano de Nicomedia no utilizó explícitamente la fórmula, pero uno de sus partidarios -el de Mileto- la introdujo en su profesión de fe, y otro -el de Abydos- la aceptaba tácitamente puesto que declaró también su adhesión a Heraclea. Este grupo era, por lo tanto, leal al poder imperial.

Existe, por otra parte, un segundo grupo cuyos miembros emplearon igualmente la fór-

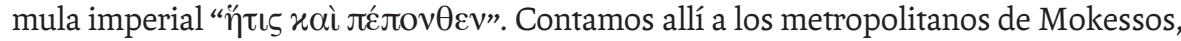
Philippoupolis, Adrianópolis, Amastris, Maroneia, Arcadiopolis y Selymbria. En este caso, sin embargo, no hay ninguna indicación que permita establecer vínculos entre sus miembros, o vínculos entre este grupo y el grupo anterior; no puede decirse, por lo tanto, si estos metropolitanos se habían sumado a la causa imperial de manera organizada o si su toma de posición era más bien individual. Cabe señalar, en todo caso, que algunos 
de los miembros de este segundo grupo iban a cambiar más tarde su posición en la controversia: los metropolitanos de Adrianópolis y Maroneia habrían de ser mencionados más adelante como opositores a la doctrina imperial (Choniates, Tesoro, col. 269a).

Frente a estos dos grupos favorables al poder imperial encontramos un tercer grupo: el de los opositores a la doctrina oficial. La Ekthesis consigna, en primer lugar, algunos datos significativos en las profesiones de fe de los metropolitanos. De acuerdo con éstas, los metropolitanos de Dristra y Proconeso admitieron haber compartido en el pasado la opinión del metropolitano de Atenas, pero añadieron enseguida que su posición había cambiado posteriormente: el metropolitano de Dristra afirmó que compartía ahora la opinión del gran oikonomo, mientras que el de Proconeso afirmó que compartía ahora la opinión de los patriarcas (Choniates, Tesoro, col. 244b y 245cd). Situación semejante en el caso del metropolitano de Methymnos. Éste declaró haber compartido anteriormente la posición del metropolitano de Corfú, pero añadió de inmediato que había cambiado su posición y que compartía ahora la opinión de los patriarcas (Choniates, Tesoro, col. 244d). ¿Por qué esa necesidad de consignar su cambio de posición, en lugar de expresar simplemente cuál era su postura al momento del interrogatorio? La situación se comprende mejor cuando llegamos al final de la primera sesión sinodal: los metropolitanos de Atenas y de Corfú se contaban, según las autoridades del sínodo, entre los que habían expresado opiniones "oscuras", y, a causa de ello, fueron sometidos a un segundo interrogatorio con objeto de precisar si aceptaban la doctrina "de los patriarcas" (Choniates, Tesoro, col. 252a-b). De ello se desprende que los metropolitanos de Atenas y de Corfú eran figuras representativas de la oposición episcopal al poder imperial, y que habían tenido en el pasado el apoyo de sus colegas de Drista, de Proconeso y de Methymnos. Estos últimos, cuya antigua posición era sin duda bien conocida por los presentes, habrían querido desvincularse de esa antigua alianza con el fin de hacer explícita su nueva adhesión a la causa imperial. Sus profesiones de fe parecen haber sido bien recibidas por las autoridades sinodales, porque no fueron examinados por segunda vez.

Los metropolitanos de Atenas y de Corfú no fueron los únicos en ser examinados por el sínodo. Sus colegas de Myra, Corinto, Larisa, Rodas, Philippes, Neopatras y Ainos debieron explicitar también su adhesión "a los patriarcas", y dos de entre éstos agregaron a su profesión de fe, sin duda bajo presión, la fórmula imperial “ $\varkappa \alpha \theta$ ” ү๊ $x \alpha i$

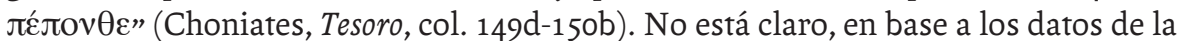
Ekthesis, si existía alguna relación entre estos metropolitanos; de hecho, no es posible establecer si los metropolitanos de Atenas y de Corfú representaban a un mismo partido o si eran líderes independientes de la oposición. ${ }^{48}$ Pero sabemos al menos que su aceptación aparente de la doctrina imperial no fue concluyente, ya que las autoridades sinodales reexaminaron más tarde la opinión de los metropolitanos de Myra, Larisa, Rodas y Neopatras (Choniates, Tesoro, col. 269a). Las sedes de Atenas, Corfú, Philippes y Ainos no volvieron a ser mencionadas, pero se examinó en reuniones posteriores a otros metropolitanos -los de Adrianópolis, Tebas y Nicea- que no habían sido interrogados durante la primera sesión sinodal (Choniates, Tesoro, col. 269a y 276b). ${ }^{49} \mathrm{El}$ hecho de que el sínodo de 1170, que condenó finalmente al metropolitano de Corfú, haya puesto a este último en relación con los metropolitanos de Adrianópolis, Neopatras, Tebas y Ainos sugiere que todos ellos habrían pertenecido desde 1166 a un mismo grupo de la oposición.

Existe, por último, un grupo integrado por obispos cuya posición es ambigua. Contamos entre éstos a los metropolitanos de Melitene, Gangres, Mitylene, Euchaita, Tebas, Serres, Lacedemonia y Parion. Estos metropolitanos no usaron la fórmula imperial ni explicitaron su acuerdo con los patriarcas, pero parece evidente que las autoridades sinodales no los consideraban disidentes, ya que no insistieron particularmente sobre sus profesiones de fe. No hay razones para pensar, por otra parte,
48. Los metropolitanos de Myra y Larisa parecen haber compartido la misma opinión teológica, pero no hay otra conexión evidente entre ellos. El metropolitano de Myra no compartía sin embargo la opinión teológica de Constantino de Corfú, lo que se ve reafirmado por su adhesión al emperador en el proceso de 1170 . No parece, por otra parte, que los metropolitanos de Atenas y Corfú hayan compartido la misma posición teológica.

49. El metropolitano de Nicea no había estado presente durante la primera sesión, donde las gnômai fueron expresadas, pero fue examinado más tarde y condenado por último (Grumel, 1989, n 1066). 
50. León de Adrianópolis fue uno de los metropolitanos que no se encontraron presentes en las sesiones del 30 de enero y el 20 de febrero de 1170 , pero cuya firma está registrada en el acta de condena del 21 de febrero. Esta situación extraña, en la que se encontraban también Juan de Tebas, Nicetas de Maroneia y Euthymios de Neopatras (opositores reconocidos de 1166) lleva a pensar que León de Adrianópolis puede haber adherido a la causa de Constantino de Corfú en 1170.

51. Nicetas de Maroneia, como ya lo hemos señalado, se contaba entre los metropolitanos que no participaron en las sesiones del

30 de enero y el 20 de febrero

de 1170, pero cuya firma está registrada en el acta de condena del 21 de febrero. Su posición en la controversia de 1166, contraria al poder imperial (tras una primera

adhesión aparente al dogma

oficial) lleva a pensar que era todavía un obispo rebelde, aliado a Constantino de Corfú, en 1170. que hayan existido vínculos entre estos metropolitanos, de entre los cuales solo uno reaparece en las sesiones posteriores: el metropolitano de Tebas, que habría cambiado su posición imparcial del principio para sumarse abiertamente a la oposición (Choniates, Tesoro, col. 269a).

Los datos, a pesar de ser a veces equívocos, permiten comprender algunas características de la disidencia dentro de la jerarquía episcopal. Sabemos, en primer lugar, que es correcto pensar en términos de "grupos" bien definidos. Cinnamos menciona, en efecto, que los opositores al dogma imperial organizaban reuniones privadas y que prohibían a sus partidarios tener entrevistas individuales con el emperador, por temor a que Manuel los convenciese de modificar su posición (Cinnamos: 254). Estas entrevistas privadas habrían tenido, cuando se llevaban a cabo, un éxito considerable. Cinnamos señala que el emperador había logrado ganar por ese medio el apoyo de varios de sus opositores, y podemos preguntarnos si los metropolitanos que declararon haber "cambiado de opinión" -los de Dristra, Proconeso y Methymnos- se habrían contado entre éstos. Sabemos, en segundo lugar, que al menos algunos de estos "grupos" que podemos identificar tenían relaciones directas con la administración patriarcal: uno de ellos habría respondido a la facción de la Gran Iglesia que defendía el dogma imperial, el otro a la facción que se oponía al emperador. Pero ¿cuántos "grupos" integraban cada posición y qué metropolitanos integraban cada uno de estos "grupos"? Más aún, ¿cómo saber si los metropolitanos que compartían una misma posición teológica se identificaban como integrantes de un "grupo" bien definido?

Comencemos por la posición favorable al poder imperial, que presenta la evidencia más débil. Hemos mencionado un grupo integrado por siete metropolitanos -los de Mokessos, Philippopolis, Adrianópolis, Amastris, Maroneia, Arcadiopolis y Selymbria-

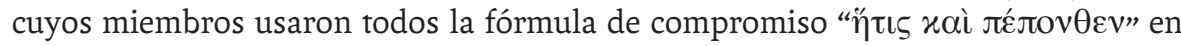
sus profesiones de fe, lo que torna evidente su adhesión al poder imperial. Estos metropolitanos nos son desconocidos en su mayoría, pero sabemos que dos de ellos -los de Adrianópolis y Maroneia- habrían provenido de la administración patriarcal. León de Adrianópolis es el mismo metropolitano que hemos visto participar de los sínodos de 1156/1157, y cuyo interés en el caso de Panteugenos sugiere que tenía vínculos estrechos con las facciones de la Gran Iglesia. No es evidente que León de Adrianópolis haya suscrito voluntariamente a la doctrina imperial durante la primera sesión sinodal de 1166, puesto que las actas posteriores lo designan entre los obispos sospechosos y las actas del sínodo de 1170 sugieren su vinculación con Constantino de Corfú, que era un opositor declarado de la doctrina imperial desde el comienzo de la controversia. ${ }^{50} \mathrm{El}$ hecho de que Constantino de Corfú haya pertenecido a la administración patriarcal -como Euthymios de Neopatras, al cual León de Adrianópolis también parece estar vinculado en las actas de 1170- reafirma que el metropolitano de Adrianópolis habría provenido de la Gran Iglesia. Nicetas de Maroneia, que cambió también su posición en el la controversia después de 1166, aparece vinculado igualmente a Constantino de Corfú, Euthymio de Neopatras y León de Adrianópolis en 1170 , lo que sugiere a su vez una procedencia de la administración patriarcal. ${ }^{51} \mathrm{El}$ hecho de que, sobre un total de siete, cinco metropolitanos de este grupo hayan ocupado sedes occidentales reafirmaría una procedencia generalizada de la administración patriarcal.

El cambio de partido de León de Adrianópolis y de Nicetas de Maroneia nos pone sin embargo en guardia contra una clasificación demasiado rápida de este grupo. Es posible que algunos de estos metropolitanos se hayan adherido voluntariamente a la doctrina imperial -a través, quizás, de sus posibles conexiones con la facción proimperial de la Gran Iglesia- pero no podemos atribuir esta posición a todos los miembros del grupo. León, Nicetas y quizás otros se habrían contados más bien entre los obispos que -como León de Dristra, Isaac de Proconeso y Nicolás de 
Methymnos- habían sido "convencidos", sin duda bajo presión, de aceptar el dogma oficial antes de la primera sesión sinodal de $1166.5^{52}$ No conocemos los detalles de sus cambios sucesivos de posición, pero el marco general de su participación en la controversia los sitúa más bien del lado de la oposición. ${ }^{53}$ Aunque no es posible afirmarlo con certeza, no hay al menos ninguna razón para creer que los miembros de este grupo hayan constituido una unidad organizada. Su adhesión individual al emperador respondía sin duda a motivos diferentes, y esta adhesión habría sido circunstancial en más de un caso. Su constitución como "grupo" en la primera sesión de 1166 es, por lo tanto, totalmente artificial.

El otro grupo que se adhirió abiertamente al poder imperial durante la primera sesión de 1166 -grupo al que vemos centrado en torno a los metropolitanos de Heraclea, de Creta y de Nicomedia- parece haber tenido, por su parte, una cierta cohesión interna, al menos por haberse mostrado de acuerdo unos con otros y por haberse citado mutuamente en más de una oportunidad. Pareciera, por otra parte, que su adhesión a la doctrina imperial era sincera, porque estos metropolitanos no fueron reexaminados ni mencionados más tarde entre los partidarios de la oposición; ;4 no es posible decir, en todo caso, cuáles eran sus motivos para adherir a la causa imperial, ni tampoco para organizarse de la manera en la que las actas nos los presentan.

Otro grupo, más claramente definido, es el de la oposición al poder imperial. Cristophoro de Myra, Teodoro de Corinto, Nicolás de Atenas, Juan de Larisa, León de Rodas, Juan de Philippes, Euthymios de Neopatras, Juan de Ainos y Constantino de Corfú expresaron, es cierto, su adhesión a la doctrina oficial en la primera sesión de 1166 (2 de marzo), pero el hecho de que hayan sido reexaminados por las autoridades sinodales en esa misma sesión señala que habrían apoyado en el pasado opiniones contrarias. Es evidente, por otra parte, que su profesión de fe fue obtenida bajo presión, porque vemos reaparecer en la sesión del 20 de marzo los nombres de Cristophoro de Myra, Juan de Larisa, León de Rodas y Euthymio de Neopatras entre los metropolitanos sospechosos (Grumel, 1989, $\mathrm{n}^{\circ}$ 1064), y en 1170 Juan de Ainos fue directamente vinculado a la acusación contra Constantino de Corfú (Petit, 1904: 48990). León de Adrianópolis y Juan de Tebas no fueron reexaminados durante la sesión del 2 de marzo, pero se contaron entre los metropolitanos considerados sospechosas en la sesión de 20 de marzo (Grumel, 1989, $\mathrm{n}^{\circ}$ 1064) y se encontraron en 1170 entre los partidarios de Constantino de Corfú. ${ }^{55}$ Nicetas de Maroneia, por su parte, no fue reexaminado el 2 de marzo, pero es mencionado entre los metropolitanos sospechosos del 20 de marzo (Grumel, 1989, $\mathrm{n}^{\circ} 1064$ ) y fue vinculado en 1170 a Constantino de Corfú. León de Drista e Isaac de Proconeso, quienes hicieron explícito su alejamiento del metropolitano de Atenas el 2 de marzo, y Nicolás de Methymnos, quien hizo explícito su alejamiento del metropolitano de Corfú en la misma sesión, deberían ser incluidos también entre los opositores al dogma oficial.

Este grupo parece haber sido bastante coherente. El vínculo entre Constantino de Corfú y las sedes de Adrianópolis, Neopatras, Tebas, Maroneia, Ainos y Methymnos sugiere que estos metropolitanos integraban un conjunto bien definido de opositores al poder imperial, quizás liderado por el metropolitano de Corfú, al menos al inicio de la controversia..$^{56}$ No está claro si Nicolás de Atenas y sus partidarios de Dristra y Proconeso formaban parte de este grupo o si representaban a un partido alternativo en la oposición, ${ }^{57}$ pero el hecho de que Nicolás y Constantino hayan provenido de la administración patriarcal sugiere que tenían objetivos en común. Sabemos, en efecto, que Constantino de Corfú y Nicolás de Atenas procedían de la Gran Iglesia, de la misma manera que varios de sus partidarios: el caso de Euthymios de Neopatras es el mejor documentado, pero ya hemos argumentado que León de Adrianópolis y Nicetas de Maroneia debían estar vinculados también a la administración patriarcal, y el mismo argumento es válido para Juan de Tebas, Juan de Ainos, Cristophoro de Myra, Juan de Larisa y León de
52. El hecho de que hayan indicado su alejamiento de los metropolitanos de Atenas y Corfú, cuyas opiniones habían compartido en primer lugar, sugiere en efecto que habían cambiado de postura bajo presión. Cf. Choniates, Tesoro, col. 244b-d y $245 \mathrm{c}-\mathrm{d}$.

53. Su aparente alejamiento de Constantino de Corfú en 1170 reafirma esta idea. Sin embargo, como Petit lo ha señalado, no se debe asumir que Constantino de Corfú haya sido responsable en 1166 de este cambio de opinión (Petit, 1904: 474).

54. Algunos de ellos, entre los cuales se cuentan Esteban de Cesárea, Miguel de Heraclea, Miguel de Nicomedia, Juan de Creta, Miguel de Abydos y Nicetas de Mileto, adhirieron de inmediato al poder imperial en 1170, lo que reafirma la sinceridad de su posición en 1166.

55. Como ya lo hemos mencionado, este vínculo explica sin duda su ausencia de las sesiones del 30 de enero y del 20 de febrero, así como su presencia (forzada) en la sesión de firma de la condena de Constantino de Corfú.

56. Como Petit lo ha señalado el metropolitano de Corfú no parece haber estado involucrado en la resistencia al poder imperial después de la sesión del 12 al 13 de mayo; este autor rechaza la opinión de Ouspenski, que atribuía a Constantino un papel oculto en la resistencia al poder imperial durante la controversia de 1166 (Petit, 1904: 474).

57. En función de las opiniones teológicas de Atenas y Corfú, no parece que hayan compartido el mismo partido. 
58. Esta interpretación, sin embargo, es sólo tentativa. Podría pensarse, por otra parte, que el gran oikonomos era un representante de la doctrina oficial, y que León de Dristra había adherido a él con el objetivo de explicitar su conformidad con el emperador. Pero, en este caso, ¿por qué se le habría pedido una profesión de fe al gran oikonomos durante la primera sesión sinodal? Y, una vez más, ¿ipor qué vincularse con el gran oikonomos en lugar de expresar simplemente una conformidad "con los patriarcas"?

59. Las listas de presencia cambian mucho a lo largo del año 1166, pero no conocemos las opiniones de todos los metropolitanos que participaron de las sesiones.
Rodas. Los casos de León de Dristra, Isaac de Proconeso y Nicolás de Methymnos son más difíciles de evaluar, pero tenemos al menos un pequeño indicio para el caso del metropolitano de Dristra. Sabemos, en efecto, que durante la sesión del 2 de marzo de 1166 León de Dristra se desvinculó de la opinión del metropolitano de Atenas para adherirse a la del "muy reverendo gran oikonomos" (Choniates, Tesoro, col. 244b-c). ¿Por qué esta alusión al gran oikonomos, en lugar de decir simplemente que adhería, como los demás, a la opinión "de los patriarcas"? Con anterioridad hemos supuesto que todos los miembros de la administración patriarcal examinados durante la sesión del 2 de marzo -entre los cuales se contaba el gran oikonomos- eran opositores más o menos moderados de la doctrina imperial; debería concluirse por ende que León de Dristra, cuyo vínculo con el gran oikonomos era sin duda bien conocido por los presentes, quería aclarar que, al igual que el gran oikonomos, él también había cambiado de posición y aceptaba ahora la doctrina oficial. ${ }^{58} \mathrm{El}$ hecho de que la profesión de fe del gran oikonomos, como la del metropolitano de Dristra, no hayan sido cuestionadas por el sínodo sugiere además que éstos no habrían sido miembros demasiado destacados de la oposición. Si esta interpretación es correcta, estaríamos frente una relación directa entre la administración patriarcal y los metropolitanos refractarios, lo que permitiría reafirmar que la oposición dentro del sínodo estaba estrechamente relacionada con la facción rebelde de la Gran Iglesia.

Existe, finalmente, un último grupo de metropolitanos cuyas opiniones expresadas el 2 de marzo no bastan para vincularlos con ninguno de los grupos antes mencionados. Contamos entre ellos a las sedes de Melitene, Gangres, Mitylene, Euchaita, Tebas, Serres, Lacedemonia y Parion, que, en su mayoría, parecen haber guardado una posición ambigua en la controversia. El hecho de que estos metropolitanos hayan expresado su adhesión al poder imperial no es significativo en sí mismo, porque las mismas expresiones de conformidad pueden ser encontradas en boca de opositores reconocidos. Es preciso señalar, en todo caso, que sus profesiones de fe fueron aceptadas por las autoridades sinodales sin mayor insistencia, a pesar de que ninguno de ellos utilizó la fórmula de

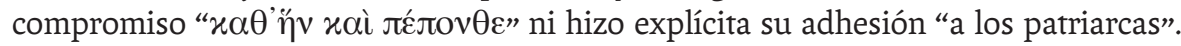
La ambigüedad persiste en la mayoría de los casos, pero no es inverosímil que se haya tratado de metropolitanos que no tenían aún bien definida su posición. Esto es sugerido al menos por el caso de Juan de Tebas, que no parece haber sido sospechoso en esta sesión del 2 de marzo, pero que se vio más tarde vinculado a los metropolitanos rebeldes. El caso de Nicolás de Parion parece proporcionar, por otra parte, el ejemplo contrario.

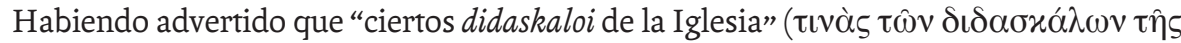

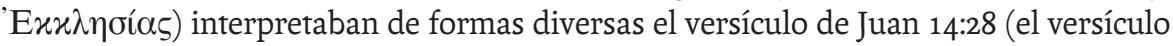
que motivó la Segunda Controversia Cristológica), Nicolás de Parion se había inclinado por aquellos que proponían entenderlo según la fórmula "de la humanidad" ( $x \alpha \tau \grave{\alpha}$

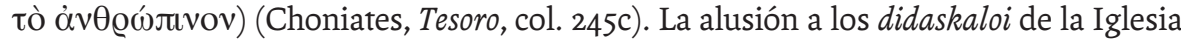
sugiere alguna relación con la administración patriarcal, donde había por cierto diáconos que defendían la posición (imperial) de "la integridad de la naturaleza humana" de Cristo. Si ese era el caso, Nicolás de Parion estaría representando la posición de un metropolitano procedente de la Gran Iglesia que suscribía a la facción minoritaria de los oficiales patriarcales que apoyaban la causa imperial.

Aunque los datos sean poco precisos y difíciles de interpretar, podemos establecer al menos algunos hechos con certeza. El primero de ellos es la oposición significativa que el poder imperial encontró entre los metropolitanos durante la Segunda Controversia Cristológica. Si partimos de la sesión sinodal del 2 de marzo de 1166, donde las opiniones de los metropolitanos presentes fueron expresadas públicamente y registradas en las actas (Choniates, Tesoro, col. 237c-248), ${ }^{59}$ contamos 15 metropolitanos cuya adhesión al poder imperial podría haber sido sincera, 9 metropolitanos cuya adhesión al poder imperial es cuestionable, y, por último, 15 metropolitanos cuya oposición al poder imperial puede ser afirmada con certeza pese a su aceptación aparente de la doctrina oficial. 
Si dejamos de lado, por otra parte, a aquellos metropolitanos cuya posición es dudosa, encontramos que existió también una cierta división geográfica entre los dos grandes grupos de metropolitanos restantes. Entre los 15 metropolitanos que apoyaban al poder imperial, tres eran occidentales o insulares -Heraclea, Derkos y Creta-, dos procedían de la región del Ponto -Mesembria y Ankhialos-, y diez eran orientales -Amaseia, Mokessos, Trebizonda, Hierapolis, Amastris, Cyzico, Nicomedia, Abydos, Mileto y Parion. Las cifras muestran, por lo tanto, una preeminencia significativa de los metropolitanos orientales entre los partidarios del poder imperial; más aún, observamos que, con la única excepción de Myra, no hubo metropolitanos orientales que se hayan adherido, al menos de manera evidente, al partido de la oposición. Los orientales que no se cuentan entre los partidarios del emperador -los de Melitene, Gangres y Euchaita- se encuentran, en efecto, entre los casos ambiguos, cuya adhesión al dogma oficial en la sesión del 2 de marzo podría haber sido sincera.

El partido de la oposición presenta cifras bastante diferentes. Como acabamos de señalar, sólo había un oriental -el de Myra- en el grupo de 15 metropolitanos refractarios al poder imperial. Los 14 restantes eran occidentales o insulares -los de Corinto, Atenas, Larisa, Philippes, Adrianópolis, Neopatras, Tebas, Ainos, Dristra, Maroneia, Methymnos, Proconeso, Rodas y Corfú. A diferencia del caso anterior, encontramos entre los opositores al poder imperial una preeminencia de metropolitanos occidentales o insulares, muchos de los cuales habrían tenido vínculos con la administración patriarcal -como ya lo hemos señalado, esta relación está atestiguada en los casos de Atenas, Corfú, Neopatras y Adrianópolis, y es probable también en los casos de Corinto, Larisa, Tebas, Ainos, Dristra, Maroneia y Rodas. Dado que una facción muy numerosa de la administración patriarcal se opuso al dogma imperial, no es sorprendente advertir que numerosos metropolitanos procedentes de la Gran Iglesia se mantuvieron leales a sus antiguos colegas de Santa Sofía.

Esto no quiere decir, por supuesto, que todos los metropolitanos procedentes de la administración patriarcal hayan sido opositores al poder imperial, ni que los metropolitanos occidentales (o insulares) hayan sido los únicos en tener vinculaciones con la administración patriarcal. En definitiva, el emperador tenía también apoyo -aunque escaso- en la administración patriarcal, y los oficiales patriarcales leales al emperador habrían reclutado para su causa a los metropolitanos procedentes de la Gran Iglesia que habían pertenecido (y aún pertenecían) a su facción. Algunos de estos metropolitanos, por otra parte, procedían de las provincias orientales: ya hemos sugerido que el metropolitano de Parion podría haber pertenecido a la Gran Iglesia, y este era sin duda el caso de otros orientales. Pero esta gran división geográfica no está desprovista de significación. De hecho, vendría a reafirmar la sospecha que hemos esbozado anteriormente: los miembros de la administración patriarcal habrían ocupado sobre todo las sedes-occidentales, insulares e incluso orientales- que estaban bajo control efectivo del Imperio, y no las sedes cuyas condiciones (económicas, militares) eran precaria a causa de la presencia turca.

No es casualidad, por otra parte, que el emperador haya recibido a lo largo de la controversia el apoyo de los metropolitanos orientales. Encontramos, de hecho, que esta adhesión selectiva puede ser aún percibida durante el juicio de 1170 contra Constantino de Corfú. La sesión sinodal del 30 de enero, en la que la doctrina del metropolitano de Corfú fue condenada unánimemente por el sínodo, tuvo una presencia predominante de obispos orientales -veintitrés orientales, de los cuales catorce procedían de sedes ocupadas o muy amenazadas por los turcos, sobre diez occidentales y seis insulares-, mientras que la oposición seguía estando representada exclusivamente por occidentales -Juan de Ainos, León de Adrianópolis, Euthymio de Neopatras, Juan de Tebas, Nicetas de Maroneia-, cuya ausencia de la sesión de discusión del 30 de enero fue sin duda obra del poder imperia. ${ }^{60}$ Más aún, seis de los obispos que se apresuraron a condenar a Constantino de Corfú en la primera sesión de 1170 -Esteban de Cesárea, Miguel de 6o. El proceso de 1170 implicó una reorganización de las alianzas de 1166. Vemos así como los metropolitanos de Dristra y de Myra, que habían sido renuentes a aceptar el dogma oficial en 116o, apoyaban en 1170 al emperador. Esto se debe a los numerosos grupos de oposición que existían en 1166 (Dristra, Myra y Corfú habían representado, en efecto, posiciones teológicas diferentes, pero coincidían al momento de oponerse a la doctrina imperial). En 116o, la oposición (muy fragmentada) a la doctrina oficial se había amalgamado provisoriamente para hacer frente al emperador, pero en 1170, cuando la controversia fue planteada por un representante de la doctrina de la "naturaleza abstracta" de Cristo, los representantes de otras posiciones (entre ellos los metropolitanos de Myra y Dristra) se adhirieron al emperador (aunque éste no representase su posición) para hacer frente a esta nueva amenaza. El hecho de que los obispos de Ainos, Neopatras, Tebas, Maroneia y Adrianópolis, ya sospechosos en 116o, hayan continuado en la oposición en 1170, sugiere que compartían un mismo partido (teológico y político). 
61. Esteban de Cesárea no participó en la sesión de las gnômai, pero participó de varias de las demás sesiones, y el hecho de que no se lo haya considerado sospechoso indica sin duda su conformidad con la doctrina oficial.

Éste, con los metropolitanos de Nicomedia y Mileto, estuvieron presentes en la condena del diácono Basilio Hagiopaulites en 1168 (Grumel, 1989, $n^{\circ} 1077$ ).
Heraclea, Miguel de Nicomedia, Juan de Creta, Miguel de Abydos y Nicetas de Mareoneia- ya habían apoyado la doctrina oficial en 1166, lo cual sugiere un respaldo estrecho al poder imperial; una vez más, no es sin duda azaroso que cuatro de estos obispos hayan sido orientales. ${ }^{61} ¿$ Es posible pensar que existía un entendimiento entre Manuel Comneno y un determinado grupo de obispos que representaba en su mayoría sedes orientales? Este acuerdo, de haber existido, no habría sido nuevo. El patriarca Atticos ya había denunciado a los metropolitanos que decidieron su deposición en el sínodo de 1147-sínodo donde el número de orientales duplicaba el de los occidentalesafirmando que eran "aduladores del emperador", lo cual no es difícil creer en virtud del interés que Manuel habría tenido en la deposición de Atticos (Choniates, Historia: 281). Pero, ¿a qué podía responder esta alianza imperial con las sedes orientales? Hay al menos dos respuestas posibles: por un lado, los metropolitanos orientales, que solían verse obligados a permanecer en Constantinopla debido a las precarias condiciones de sus sedes, necesitaban sin duda el apoyo (económico y político) del poder imperial; por otro lado, es posible que los metropolitanos orientales no procedentes de la administración patriarcal hayan intentado ganar, por medio de su adhesión a Manuel Comneno, los beneficios de esa alianza imperial de la que los miembros de la Gran Iglesia gozaban desde el comienzo del siglo.

\section{Los conflictos eclesiásticos y la Iglesia provincial}

Fuesen cuales fuesen las causas de la disidencia entre los metropolitanos-conflictos heredados de la administración patriarcal, competencia por la alianza imperial, condicionamientos geográficos, designios eclesiológicos-, es evidente, en todo caso, que cualquier conflicto eclesiástico tenía serias consecuencias sobre la organización de la Iglesia provincial. La resistencia a la eclesiología imperial, la deposición de patriarcas, la deposición de metropolitanos, el debilitamiento de la autoridad episcopal, la posible intervención de las diócesis, ponían en peligro el modelo Comneno de una iglesia mediadora entre el poder imperial y la población de las provincias del Imperio. Los casos de Miguel Italikos en Philippopolis y de Eustathios Kataphloron en Tesalónica ilustran hasta qué punto las rivalidades entre los eclesiástico podían alterar el estado de las sedes provinciales.

Veamos, en primer lugar, el caso de Italikos, que era metropolitano de Philippopolis hacia mediados del siglo XII. Sabemos que Italikos tenía problemas en su diócesis con un cierto Kampsorymes, cuya identidad es mal conocida, y que su amigo Teodoro Prodromo le aconsejó buscar el apoyo del patriarca Nicolás Mouzalon (Browning, 1962: 279-297, aquí 287-8; Gautier, 1972: 27). Hay aquí un primer aspecto de interés. ¿Por qué Prodromo le habría aconsejado recurrir al patriarca, habiendo otras instancias menores a las cuales dirigirse para un asunto provincial de pequeña envergadura? Se podría suponer, en primer lugar, que el asunto no era realmente de pequeña envergadura. Robert Browning ha sugerido que Kampsorymes tenía vínculos con el hereje Niphon, lo cual habría justificado sin duda el recurso al apoyo especial del patriarca (Ntoeninh, 1962: 296). Sin embargo, éste no parece haber sido el caso. Paul Gautier y Michael Angold han señalado que la actitud flexible del sínodo respecto de Kampsorymes no permite reconocer en él un hereje (Gautier, 1972: 27; Angold, 1995: 175). Por otra parte, el hecho de que el patriarca Mouzalon haya sancionado a Kampsorymes por no haber intentado recuperar el favor de Italikos revela que el problema no era muy serio: no se recomendaba sin duda a un hereje que pidiese simplemente la gracia de su metropolitano.

La recomendación del patriarca sugiere, de hecho, que el asunto de Kampsorymes no era más que una disputa entre el metropolitano y un clérigo rebelde de su iglesia, 
lo que la carta de Prodromo a Italikos parece reafirmar. En dicha carta, Prodromo hace una comparación entre Kampsorymes y un personaje similar que residía en Constantinopla, donde se lo veía "andar de un lado a otro entre calles y callejuelas, en las plazas, en los edificios públicos y en las iglesias", armando escándalo y actuando como un pequeño agitador, de la misma manera en que Italikos le habría descripto sin duda a Kampsorymes (Browning, 1962: 287-8). Pero, una vez más, si Italikos no debía lidiar más que con un clérigo refractario, ¿por qué se vio en la necesidad de dirigirse al patriarca en busca de apoyo? El desarrollo del caso sugiere al menos una respuesta. Sabemos que Kampsorymes realizó una denuncia contra Italikos en Constantinopla, y que el patriarca tomó inmediatamente el partido de Italikos: Mouzalon acusó a Kampsorymes de no haber buscado la ayuda de los obispos provinciales o de un sínodo local a fin de verse reconciliado con su metropolitano, y de haberse dirigido directamente al patriarca de manera anticanónica para realizar sus denuncias. El sínodo permanente desacreditó sin embargo la posición de Mouzalon. Habiendo aceptado el relato de Kampsorymes, según el cual las instancias locales no lo habían ayudado a resolver el conflicto, el sínodo declaró que no había actuado de manera anticanónica y se prestó aparentemente a escuchar sus acusaciones (Syntagma III: 321).

No conocemos el desenlace del caso de Kampsorymes, pero es probable que éste haya sido desfavorable para Italikos. Esto habría influido quizás en la renuncia de Italikos a su sede episcopal, cuyas circunstancias ilustran aún con mayor detalle sus problemas con el sínodo permanente: cuando Italikos estaba a punto de abandonar su sede -forzado sin duda por el debilitamiento de su posición política-, intentó imponer al sínodo, como condición para su renuncia, el nombramiento del oikonomos de su iglesia como nuevo metropolitano de Philippopolis. La respuesta del sínodo, según el testimonio de Balsamon, fue severa: "Italikos no fue escuchado, y se le respondió que si el obispo no estaba autorizado a legar o a obsequiar los bienes adquiridos después de su ordenación gracias a los ingresos de su iglesia, menos aún podía donar la dignidad episcopal" (Syntagma II: 99; Angold, 1995: 17).

La oposición entre Italikos y el sínodo es muy evidente. Comprendemos mejor así el peligro que un pequeño asunto local implicaba para un metropolitano que se sabía vigilado por sus adversarios; comprendemos mejor también el recurso al patriarca, que era el único que podía tratar de proteger a Italikos del sínodo permanente. El hecho de que Kampsorymes haya estado dispuesto a denunciar a su metropolitano sugiere además que estaba seguro de contar con el apoyo del sínodo, y no es sorprendente observar como este último se sirvió rápidamente de este asunto menor para oponerse al patriarca -cuyos conflictos con los obispos del sínodo están bien documentados-y al propio Italikos, quien se vio forzado a abandonar eventualmente su sede (Angold, 1995: 175-6).

Italikos no fue, en cualquier caso, el único metropolitano en tener conflictos con el sínodo permanente. Sabemos que Eustathios de Tesalónica fue víctima, algunos decenios más tarde, de las acusaciones de un grupo de habitantes de su ciudad metropolitana. Sus escritos no han registrado más que un nombre entre los de sus acusadores, el de "León el pobre", un individuo que "ya hubiese muerto de hambre si no hubiese sido alimentado por la caridad eclesiástica", aunque otros pasajes contienen también alusiones vagas a "uno o dos entre los laicos distinguidos y los aristócratas" y a los "miembros del clero, que son numerosos y no revisten mucha importancia" (Tafel, 1832 [= Eusthatios Opuscula]: 160, 164). Los opositores a Eustathios, aunque muy mal conocidos, parecen políticamente significativos: incluían a miembros del clero, a laicos poderosos y quizás a agitadores como León. No conocemos el motivo de las acusaciones, y el desarrollo del proceso es difícil de reconstruir a causa de la imprecisión del relato de Eustathios, pero sabemos al menos que un "grupo de obispos" (Eustathios, Opuscula: 160) intervino para examinar las actividades de la diócesis. Como Michael 
62. Cf. sin embargo, Kazhdan y Franklin (1984: 136).
Angold lo ha señalado, el único "grupo de obispos" que podía juzgar las actividades de un arzobispo era el sínodo permanente (u obispos delegados por éste), por lo que debemos pensar que las denuncias contra Eustathios ocasionaron la intervención directa del sínodo en la sede de Tesalónica (Angold, 1995: 185). ${ }^{62}$

En uno de sus escritos, Eustathios describe en detalle la violencia de la intervención. Los obispos sometían a examen "su vida, sus palabras, su alma, sus movimientos y todos sus asuntos físicos". Investigaban su vida, sus palabras, incluso sus sueños para saber si pensaba "de manera canónica o de otra manera". Eustathios se quejaba también las humillaciones de las que había sido objeto durante la intervención de su sede. Según sus palabras, los obispos lo habían castigado como "al más bajo de los esclavos, alterando las cosas para que el padre se convierta en hijo, el hombre libre en esclavo, el heleno en bárbaro, el sabio en ignorante, y, peor aún, en hombre común el gran arzobispo y en laico el que está por encima del pueblo" (Eustathios, Opuscula: 164). Por más que la descripción de Eustathios es evidentemente retórica, no cabe duda que la intervención del sínodo causó una significativa perturbación en su sede.

\section{Síntesis y conclusiones}

El abordaje desarrollado hasta aquí puede ser considerado ilustrativo de la compleja situación interna de la Iglesia durante el siglo XII. La evidencia analizada permite identificador tres grandes fuentes de conflicto dentro de la institución eclesiástica:

(1) En primer lugar, parece clara la existencia de una división entre metropolitanos provenientes de la administración patriarcal-quienes ocupaban en su mayor parte sedes occidentales y permanecían generalmente en provincia- y metropolitanos externos a la administración patriarcal (monjes, laicos, clero de otras iglesias, etc.) -quienes ocupaban en su mayor parte sedes orientales y residían a menudo en Constantinopla. El último grupo, que controlaba el sínodo permanente y sentía recelo hacia los miembros de la jerarquía episcopal provenientes de la administración patriarcal debido a su alianza con el poder imperial, habría interferido deliberadamente en las sedes provinciales controladas por antiguos miembros de la Gran Iglesia (como lo ilustra el caso de Miguel Italikos y Eustathios Kataphloron) y habría buscado consolidar su cooperación con el poder imperial en detrimento de la antigua alianza que éste mantenía con los miembros de la Gran Iglesia (como lo ilustra la Segunda Controversia Cristológica).

(2) En segundo lugar, es evidente la existencia de divisiones internas dentro de la administración patriarcal (ilustradas por los problemas del patriarca Atticos con el clero de Santa Sofía, de Jorge Tornikes con Panteugenos, de Basilio con Miguel y Nicéforo Basilakes, etc.). Las rivalidades facciosas dentro de la Gran Iglesia, por su parte, representaban una fuente de inestabilidad dentro del patriarcado de Constantinopla y facilitaban que el sínodo permanente -dominado, como lo hemos sugerido ya, por obispos que pretendían limitar la influencia de la administración patriarcal-ganase injerencia sobre sus asuntos internos.

(3) En tercer lugar, es indudable la existencia de conflictos entre los metropolitanos provenientes de la administración patriarcal, que se veían ligados a las facciones internas de la Gran Iglesia aún después de haberla abandonado para ocupar sedes provinciales (como lo ilustra la Primera Controversia Cristológica).

Todos estos antecedentes dan cuenta de una Iglesia dividida en facciones que competían tanto para consolidar su poder dentro de la institución eclesiástica como para consolidar su posición frente al poder imperial. Una de las consecuencias más directas 
de la alianza entre Alexis I y la administración patriarcal, de hecho, había sido el incremento de las ambiciones políticas del clero de la Gran Iglesia y de los metropolitanos que surgían de ella (como lo sintetizan los puntos 2 y 3 ). Ese grupo eclesiástico nunca llegó a cuestionar formalmente la autoridad imperial sobre la Iglesia -al menos, no del modo abierto en que lo había hecho Cerulario y sus seguidores en el siglo XI- porque, a pesar de todo, era consciente de que su consolidación política, social y económica se derivaba de su alianza con el emperador, pero sí pretendió aumentar paulatinamente su independencia y privilegiar sus intereses en detrimento de los intereses de la dinastía reinante. En ese sentido, la administración patriarcal se había tornado en un aliado difícil para los herederos de Alexis I.

Al momento del ascenso al trono de Manuel I, la alianza entre el poder imperial y la administración patriarcal ya había cumplido su objetivo principal. Los Comneno se habían servido de la Iglesia tanto para lograr una consolidación de la esfera pública del Estado frente a las ambiciones de la aristocracia laica como para sentar las bases de una reestructuración cívico-administrativa del Imperio. En el corto y mediano plazo, esa alianza puede ser considerada exitosa. A lo largo de los sucesivos reinados de los Comneno, e incluso durante el período posterior a la caída de la dinastía, es posible identificar ejemplos específicos de metropolitanos que demostraron lealtad al Estado imperial, compromiso político hacia sus congregaciones y eficiencia en su rol de mediadores entre el territorio provincial y la capital. Sin embargo, estos ejemplos no pueden ser considerados plenamente representativos de la actividad desempañada por los miembros de la jerarquía eclesiástica, y, tal como lo ilustra el análisis previo, la conflictividad dentro de la institución fue en aumento a partir de la segunda mitad del siglo XII. Pese a que la información provista por las fuentes es a menudo elusiva y difícil de interpretar, la evidencia sugiere que Manuel I se vio en la necesidad de buscar el apoyo de los metropolitanos orientales -aquellos que, en su mayor parte, no tenían vínculo con la administración patriarcal- a fin de contrarrestar las ambiciones del clero de la Gran Iglesia y de los metropolitanos surgidos de ella. Esta medida política-que implicaba revertir la alianza creada por Alexis I- habría tenido consecuencias significativas, ya que los metropolitanos orientales -quienes, por el hecho de residir mayoritariamente en Constantinopla, controlaban el sínodo permanente- se habrían servido del nuevo apoyo del poder imperial para confrontar con los metropolitanos provenientes de la Gran Iglesia (como los sintetizan los puntos 1 y 2). El resultado de esto fue sin duda el incremento de la conflictividad dentro de la institución eclesiástica y, en términos concretos, la disrupción de las sedes provinciales, especialmente en occidente. El análisis previo, en ese sentido, muestra que la estrategia política de los Comneno -la articulación del territorio imperial sobre la estructura de la Iglesia- fue frágil, imperfecta y fácilmente vulnerable, y sugiere que las debilidades de esa misma estrategia deben ser consideradas como uno de los factores que facilitó, e incluso quizás promovió, la crisis política propia de las últimas décadas del siglo XII.

\section{Notas}

19 Para las listas de presencia de este decenio, Cf. Grumel (1989: $\mathrm{n}^{\circ}$ 1055); Papadopoulos-Kerameus [= AIS] (1891-1898, IV: 106-7, sesión de febrero de 1164); Grumel (1989: n 1068, Syntagma V, 95-8, sesión de abril de 1166); Grumel (1989: n 1075a, sesión de noviembre de 1167); Grumel (1989: n 1077, sesión enero de 1168); Grumel (1989: $n^{\circ}$ 1085, sesión marzo 1169); Grumel (1989: $n^{\circ}$ 1086, PapadopoulosKerameus, AIS, IV, 107-8, sesión noviembre de 1169). No hemos tenido acceso a las listas de presencia de abril de 1166 y de marzo 1168 (cf. Grumel, 1989: n 1072 y 1078). (En página 97) 
23 Sobre un total de 21 obispos, nueve eran orientales, diez eran occidentales y dos eran insulares. El asunto discutido en esta sesión -la prohibición a los lectores de desempeñar cargos seculares- fue planteado por un obispo occidental, Romano de Apros, pero no parece probable que haya podido interesar especialmente a los occidentales. El otro acontecimiento importante de este año -la condena de Eirenikos- no habría interesado tampoco a los occidentales de modo especial, porque Eirenikos era un monje oriental. Cf. Grumel (1989: n 1119), Laurent (1934: 298-315, aquí 310-11). (En página 97)

26 Sobre un total de 16 obispos, once habrían sido orientales, cuatro habrían sido occidentales, y uno habría sido insular. La lectura de algunos nombres presenta problemas. Juan "de Herakles" es nombrado como Juan "de Arakliaj" y colocado entre Iconio y Mokessos. Como Grumel lo ha señalado, el lugar que la sede ocupa en la lista de presencia indica que se trata de una metrópolis, pero no puede ser Heraclea, ya que ésta estaba ocupada por Teodoro (mencionado por este nombre en la misma lista y en otras listas de período); habría que pensar entonces en Herakles, pero Grumel señala que Herakles, siendo un arzobispado, debería encontrarse al final, después de Derkos. Teniendo en cuenta, sin embargo, que hay otros errores en la jerarquía de las sedes (Nicea, por ejemplo, es mencionada después de Melitene), es posible considerar que podría tratarse del arzobispado de Herakles. El caso de Constantino “de Vlachioj” es problemático. Seguimos aquí a Grumel, que la interpreta como Constantino "de Euchaita”. Existe, por último, el caso de Basilio “de Aprnatzvoj”, que, como señala Grumel, no puede interpretarse como "Apros", porque la sede de ese nombre estaba ocupada por otro titular. Grumel considera que se trata de un error en la tradición manuscrita, lo que hace la procedencia de Basilio prácticamente imposible de establecer. No lo hemos considerado entre los signatarios. Cf. Grumel (1989: n 1131a). (En página 97)

47 El criterio utilizado para delimitar esos grupos puede ser fácilmente puesto en cuestión, porque el hecho de adherir a la opinión de otro obispo no era inhabitual en las sesiones sinodales. En la sesión del 30 de enero de 1170, el metropolitano de Esmirna adhirió a la opinión del obispo de Cesárea, los de Nazianzo y Abydos adhirieron a la del metropolitano de Dristra, y el de Kios adhirió a la del metropolitano de Arcadiopolis, pero no podemos ver allí grupos definidos: el metropolitano de Esmirna adhirió sin duda al de Cesárea porque éste había sido el primero en hablar, y los de Nazianzo, Abydos y Kios adhirieron a Dristra y Arcadiopolis (respectivamente) porque éstos habían hablado inmediatamente antes que ellos (Petit, 1904: 479 ss). El caso de la sesión de las gnômai del 2 de marzo de 1166, sin embargo, parece ser diferente: en principio, no se trataba de sumarse a la opinión de otro obispo para evitar especificar su posición, porque algunos de ellos desarrollaron con detalle sus creencias antes de afirmar su acuerdo con otros miembros del sínodo (cf., por ejemplo, Abydos y Creta). Por otra parte, algunos metropolitanos (entre los que se cuentan Derkos, Ankhialos, Abydos y Mileto) expresaron su adhesión a los metropolitanos (Creta, Nicomedia) que habían hablado mucho antes que ellos. ¿Por qué hacer alusión a Creta o Nicomedia, si era más representativo mencionar a Heraclea, que había hablado en primer lugar y cuya opinión era la misma (algunos de ellos, de hecho, expresaron su adhesión a "Heraclea y Nicomedia/Creta")? Dado que Cinnamos menciona la existencia de "grupos” organizados, es probable que las citas respectivas de la sesión de las gnômai sean ilustrativas de alianzas entre los metropolitanos: varios de ellos habrían indicado así su adhesión al líder de un grupo (Heraclea, Creta, Nicomedia), como otros indicaban su alejamiento de otros jefes de grupo (Atenas, Corfú), cuyas opiniones habían decidido abandonar. Algunos otros detalles reafirman esta impresión y sugieren que estos "grupos” de metropolitanos tenían vínculos con la administración patriarcal. El metropolitano de Dristra afirmó haber escuchado las opiniones del gran oikonomos y haberse sumado a ésta; ahora bien, no es posible que haya decidido sumarse al oikonomos durante la sesión, porque éste expresó su opinión después de la del metropolitano de Dristra. De ello se deduce que este último había escuchado al gran oikonomos en reuniones anteriores. Mismo caso con el metropolitano de Parion, quien declaró conocer los debates doctrinales de la Gran Iglesia. Estas vinculaciones (entre los metropolitanos o entre los metropolitanos y el clero patriarcal) ilustran sin duda la formación de grupos mencionada por Cinnamos). (En página 110) 


\section{Q Bibliografía}

" Angold, M. (1995). Church and Society in Byzantium under the Comneni (1081-1261). Cambridge: Cambridge University Press.

" Browning, R. (1962). “Unpublished Correspondence between Michel Italicus, Archbishop of Philippopolis, and Theodore Prodromos", Byzantinobulgarica, 1, pp. 279-297.

" Darrouzès, J. (1981). Géographie ecclésiastique de l'Empire byzantin, Tome I, Notitiae episcopatuum Ecclesiae Constantinopolitanae. Paris: Institut Français d'Études Byzantines.

» Darrouzès, J. (1970a). Georges et Dèmètrios Tornikès. Lettres et Discours. Paris: Centre National de la Recherche Scientifique.

»Darrouzès, J. (197ob). “Listes synodales et notitiae”, REB, 28, pp. 57-96.

" Frankopan, P. (2007). "Kinship and the Distribution of Power in Komnenian Byzantium", English Historical Review Vol. CXXII n 495, 1-34.

》 Garzya, A. (1984). Nicephori Basilacae orationes et epistolae. Teubner: Leipzig.

" Gautier, P. (1972). Michel Italikos: Lettres et discours. Paris.

" Gouillard, J. (1978). "Quatre procès de mystique à Byzance (vers 960-1143). Inspiration et autorité", REB, 36, pp. 5-81.

" Gouillard, J. (1967). “Le synodikon de l'Orthodoxie. Édition et commentaire, TM, 2, pp. 219-20.

" Grumel, V. (1989). Les regestes des actes du patriarcat de Constantinople, vol. 1: Les actes des patriarches, Fascicules II-III, [2 ${ }^{\circ}$ ed. corregida por ]. Darrouzès]. Paris: Institut François d'Études Byzantines,.

" Grumel, V. (1970). “Léon métropolite d’Amasée (XIle siècle)”, REB, 28, pp. 57-96.

" Kazhdan, A. y Franklin, S. (1984). Studies on Byzantine literature of the eleventh and twelfth centuries. Cambridge: Cambridge University Press.

" Laurent, V. (1934). "Réponses canoniques inédites du patriarcat byzantin", EO, vol. 33, № 175 , pp. 298-315.

» Leone, P. L. M. (1972). loannis Tzetzae epistulae. Leipzig.

" Magdalino, P. (2002). The Empire of Manuel I Komnenos, 1143-1180. Cambridge, Cambridge University Press.

》Meineke, A. (1836). loannis Cinnami epitome rerum ab loanne et Alexio Comnenis gestarum. Bonn.

» Mullett, M. y Smythe, D. (eds.) (1996). Alexios I Komnenos. Belfast: Belfast Byzantine Texts and Translations.

》Papadopoulos-Kerameus, A. (1909). Varia Graeca sacra. San Petesburgo.

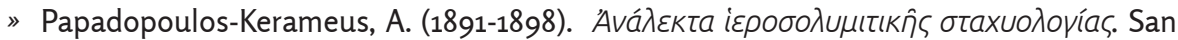
Petesburgo.

"Petit, L. (1904). "Documents inédits sur le concile de 1166 et ses derniers adversaires", W, 11.

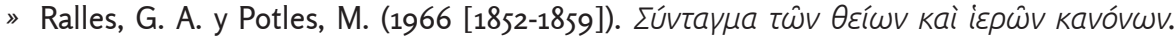
Atenas. 


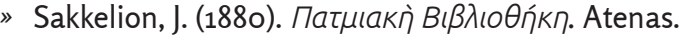

"Stieronon, L. (1963). “Notes de titulature et de prosopographie byzantine: Adrien (Jean) et Constantin Comnène, sébastes”, REB, 21, pp. 179-198.

» Tafel, T. L. F. (1832). Eustathii Thessalonicensis Opuscula. Frankfurt.

» Tiftixoglou, V. (1969). “Gruppenbildungen innerhalb des Konstantinopolitanischen Klerus während der Komnenenzeit“, BZ, 62, pp. 25-72.

»Van Dieten, A. (1975). Nicetae Choniatae Historia. Berlin-New York.

»Vroynis, S. (1971). The Decline of Medieval Hellenism in Asia Minor and the Process of Islamization from the Eleventh through the Fifteenth Century. Beckerley-Los Angeles-Londres: University of California Press.

\section{Abreviaturas}

»BMGS = Byzantine and Modern Greek Studies

» $B Z=$ Byzantinische Zeitschrift

» $P G=$ Patrologia Graeca

» REB = Revue des Études Byzantines

» $T M=$ Travaux et Mémoires 